ARTICLE

https://doi.org/10.1038/s41467-019-08404-w

\title{
Satb1 regulates the effector program of encephalitogenic tissue Th17 cells in chronic inflammation
}

Keiko Yasuda1,2,3, Yohko Kitagawa², Ryoji Kawakami², Yoshitaka Isaka ${ }^{3}$, Hitomi Watanabe ${ }^{4}$, Gen Kondoh ${ }^{4}$, Terumi Kohwi-Shigematsu ${ }^{5}$, Shimon Sakaguchi, ${ }^{1,2} \&$ Keiji Hirota ${ }^{2,4}$

The genome organizer, special AT-rich sequence-binding protein-1 (Satb1), plays a pivotal role in the regulation of global gene networks in a cell type-dependent manner and is indispensable for the development of multiple cell types, including mature $\mathrm{CD} 4^{+} \mathrm{T}, \mathrm{CD} 8^{+} \mathrm{T}$, and Foxp3 ${ }^{+}$regulatory $\mathrm{T}$ cells in the thymus. However, it remains unknown how the differentiation and effector program of the Th subsets in the periphery are regulated by Satb1. Here, we demonstrate that Satb1 differentially regulates gene expression profiles in nonpathogenic and pathogenic Th17 cells and promotes the pathogenic effector program of encephalitogenic Th17 cells by regulating GM-CSF via Bhlhe40 and inhibiting PD-1 expression. However, Satb1 is dispensable for the differentiation and non-pathogenic functions of Th17 cells. These results indicate that Satb1 regulates the specific gene expression and function of effector Th17 cells in tissue inflammation.

\footnotetext{
${ }^{1}$ Laboratory of Experimental Immunology, Institute for Frontier Life and Medical Sciences, Kyoto University, Kyoto 606-8507, Japan. ${ }^{2}$ Department of Experimental Immunology, Immunology Frontier Research Center, Osaka University, Osaka 565-0871, Japan. ${ }^{3}$ Department of Nephrology, Osaka University Graduate School of Medicine, Osaka 565-0871, Japan. ${ }^{4}$ Laboratory of Integrative Biological Science, Institute for Frontier Life and Medical Sciences, Kyoto University, Kyoto 606-8507, Japan. ${ }^{5}$ Department of Orofacial Sciences, University of California, San Francisco, CA 94143, USA. These authors contributed equally: Yohko Kitagawa, Ryoji Kawakami. Correspondence and requests for materials should be addressed to S.S. (email: shimon@ifrec.osaka-u.ac.jp) or to K.H. (email: hkeiji@infront.kyoto-u.ac.jp)
} 
nterleukin-17 (IL-17)-producing T-helper 17 (Th17) cells play dichotomous roles in the host defense against pathogens at mucosal surfaces and in the pathogenesis of many inflammatory and autoimmune diseases, such as psoriasis, inflammatory bowel disease, rheumatoid arthritis, and multiple sclerosis ${ }^{1-7}$. Th17 cell differentiation from naive $\mathrm{T}$ cells is initiated by transforming growth factor $\beta 1$ (TGF $\beta 1$ ) and IL-6 and it is further stabilized by environmental cues including cytokines such as IL$1 \beta$, IL-23, ligands for the aryl hydrocarbon receptor, hypoxia, and a high sodium chloride concentration ${ }^{8-16}$. Thus, the terminal differentiation and effector functions of Th17 cells are tightly regulated by intrinsic and extrinsic cues in local tissue environments.

Th17 cells exhibit a high degree of functional heterogeneity. The pathogenic effector program of Th17 cells is induced by IL23 signaling and is characterized by GM-CSF production ${ }^{17-19}$. Induction of Th17 cells by TGF- $\beta 1$ and IL- 6 in vitro is not sufficient to cause autoimmune tissue injury in experimental a

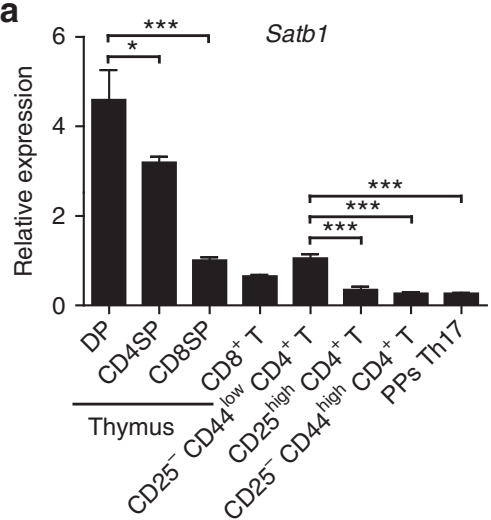

C

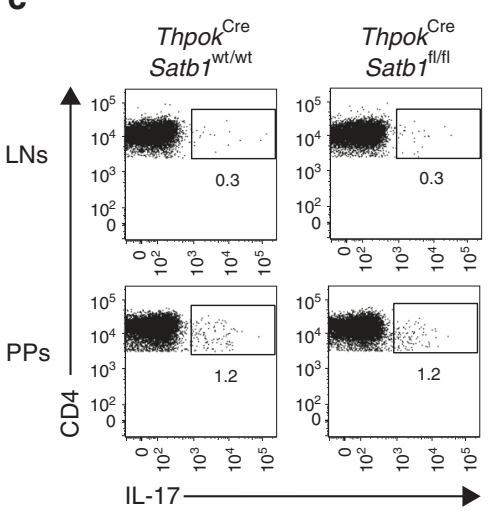

d

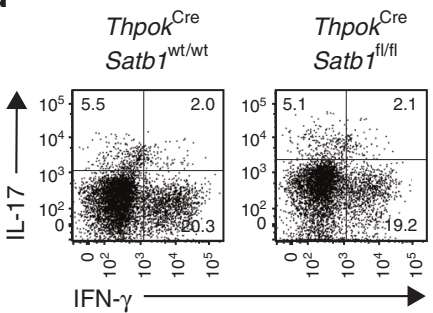

e

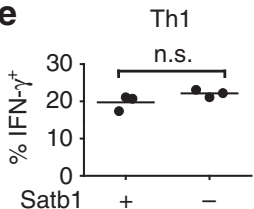

Satb1 + -

$\mathbf{f}$

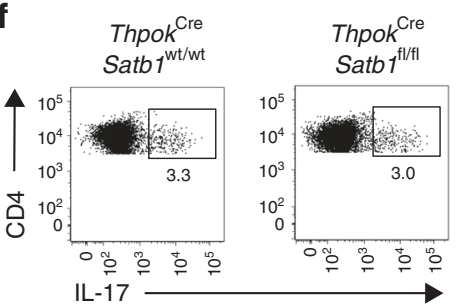

b
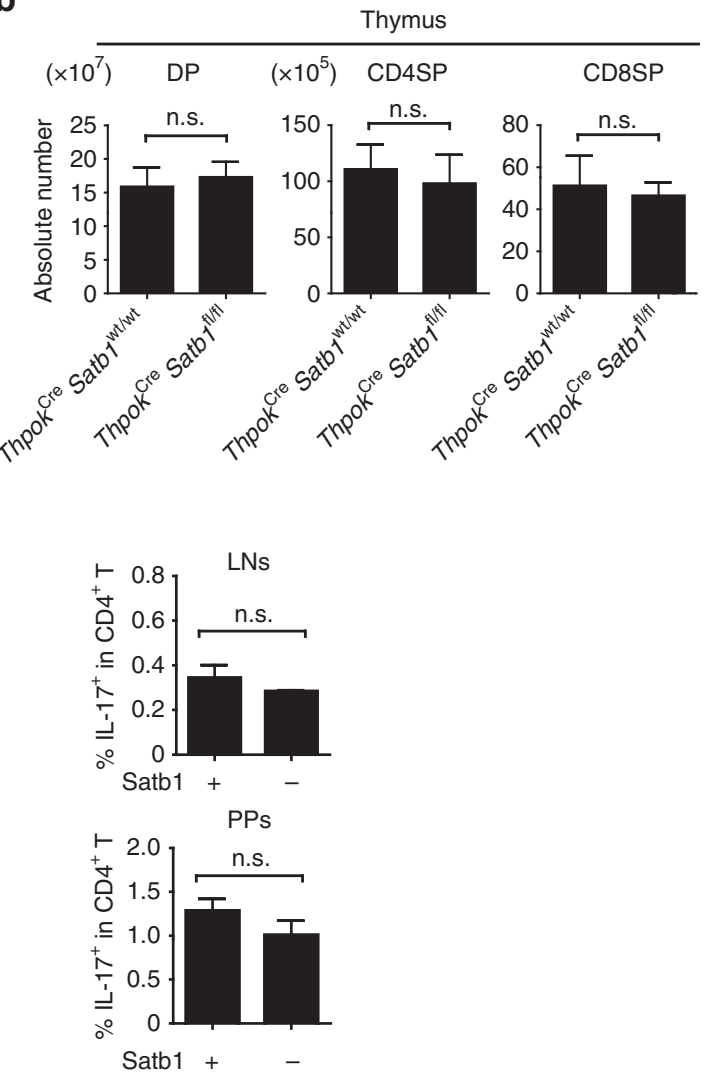

IL-17
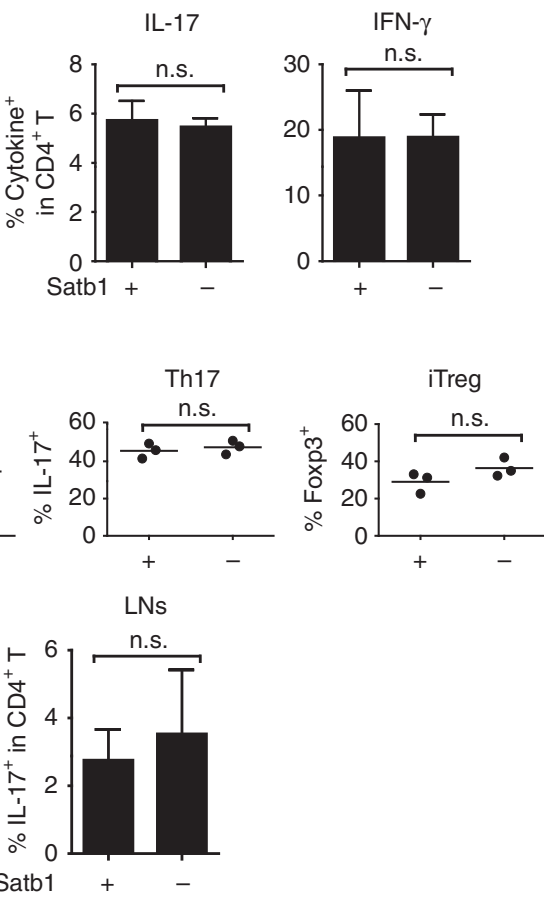
autoimmune encephalomyelitis (EAE), but when induced by IL$1 \beta$, IL-6, and IL-23 or TGF- $\beta 3$, Th17 cells trigger EAE, consistent with the critical roles of IL-23 signaling in the terminal differentiation of Th17 cells ${ }^{17,}$, 20-23. Furthermore, GM-CSF has been identified as a pathogenic signature cytokine of Th17 cells. Driven by IL-1 $\beta$ and IL-23-mediated signaling events along with transcription factor, ROR $\gamma$ t, GM-CSF causes local tissue inflammation by recruiting inflammatory myeloid cells ${ }^{18,19,24-26}$. Recent transcriptomic studies have attempted to capture the true physiological state of pathogenicity by using ex vivo Th17 cells and identified Gpr65, Toso, and Plzp as novel genes promoting Th17 pathogenicity and CD5 antigen-like (CD5L) as a repressor of Th17 cell-mediated disease ${ }^{27,} 28$. However, apart from the identification of these various determinants of Th17 pathogenicity, a cohesive molecular mechanism that allows for the distinct functioning of pathogenic and non-pathogenic Th17 cells remains to be identified.

Here, we identified special AT-rich binding protein 1 (Satb1), a genome organizer, as a crucial regulator of the pathogenic function of encephalitogenic tissue Th17 cells. We found that Satb1 is dispensable for the differentiation and non-pathogenic function of Th17 cells in the gut but plays a pivotal role in the effector functions of pathogenic Th17 cells, including GM-CSF production via regulation of Bhlhe 40 and PD-1 expression in EAE mice. Moreover, gene expression in Th17 cells from the gut and inflamed spinal cord is differentially regulated by Satb1. Thus, our results indicate that inflammatory cues modulate Satb1 to control the specific effector program of tissue Th17 cells.

\section{Results}

Satb1 is dispensable for non-pathogenic Th17 cells. Since Satbldeficient mice exhibit post-natal lethality ${ }^{29}$, we generated Thpok ${ }^{\mathrm{Cre}} \mathrm{Satb} \mathrm{f}^{\mathrm{f} / \mathrm{fl}}$ mice in which Satbl is conditionally deleted in $\mathrm{CD}^{+} \mathrm{CD}^{-}$thymocytes and peripheral $\mathrm{CD} 4^{+} \mathrm{T}$ cells $^{30}$. To investigate the differentiation and function of Th17 cells under steady-state conditions, we conducted ex vivo analysis of cells from Thpok ${ }^{\mathrm{Cre}}$ Satb1 $1^{\mathrm{wt} / \mathrm{wt}}$ and Thpok ${ }^{\mathrm{Cre} S}$ Satb $1^{\mathrm{fl} / \mathrm{fl}}$ mice. Satb1 was highly expressed in $\mathrm{CD}_{4}^{+} \mathrm{CD}^{+}$thymocytes, as previously reported ${ }^{31-34}$, and the expression was dramatically decreased in peripheral $\mathrm{CD}^{+}{ }^{+} \mathrm{T}$ and $\mathrm{CD} 4^{+} \mathrm{T}$ cells, including $\mathrm{CD} 25^{-} \mathrm{CD} 44^{\text {low }}$ $\mathrm{CD} 4^{+}$naive $\mathrm{T}, \mathrm{CD} 25^{\text {high }} \mathrm{CD} 4^{+}$regulatory $\mathrm{T}$ (Treg), and $\mathrm{CD} 25^{-}$ $\mathrm{CD} 44^{\text {high }} \mathrm{CD}^{+}$effector $\mathrm{T}$ cells. Satb1 expression was also decreased in Peyer's patches (PPs) eYFP ${ }^{+} \mathrm{CD}^{+} \mathrm{T}$ (Th17) cells purified from an Ill7a Cre $R 26 R^{\mathrm{eYFP}}$ fate reporter strain ${ }^{35}$ (Fig. 1a and Supplementary Fig. $6 \mathrm{a}$ and $6 \mathrm{c}$ for gating strategies). Thpok Cre Satb $1^{\mathrm{fl} / \mathrm{fl}}$ mice had the normal numbers of $\mathrm{CD}^{+}{ }^{+} \mathrm{CD} 8^{+}, \mathrm{CD} 4^{+}$ $\mathrm{CD}^{-}$, and $\mathrm{CD} 4^{-} \mathrm{CD}^{+}$thymocytes and the similar frequencies of IL-17-producing CD4 $4^{+}$T cells in lymph nodes (LNs) and PPs compared with Thpok Cre Satb $1^{\mathrm{wt} / \mathrm{wt}}$ mice (Fig. 1b, c). Upon adoptive transfer into Rag $2^{-I-}$ mice, naive T cells from Thpok Cre Satb $1^{\mathrm{f} / \mathrm{fl}}$ mice differentiated into IL-17- or IFN- $\gamma$-producing Th cells with the same efficiency as cells from Thpok Cre Satb $1^{\mathrm{wt} / \mathrm{wt}}$ mice after homeostatic proliferation (Fig. 1d). By culturing naive $\mathrm{CD} 4^{+} \mathrm{T}$ cells from Thpok ${ }^{\text {Cre }} S a t b 1^{\mathrm{f} / / \mathrm{fl}}$ and Thpok Cre Satb $1^{\mathrm{wt} / \mathrm{wt}}$ mice, we further examined whether Satb1 was required for the differentiation of Th1, Th2, Th17, and induced Treg (iTreg) subsets in vitro. Although Satb1 expression was relatively increased under Th17 culture conditions (Supplementary Fig. 1), the differentiation of IFN- $\gamma$-, IL-4-, IL-17-, and Foxp3-expressing $\mathrm{CD} 4^{+} \mathrm{T}$ cells was not dependent on Satb1 expression in naive $\mathrm{T}$ cells (Fig. 1e). Although it was previously reported that the knockdown of Satb1 in human $\mathrm{CD} 4^{+} \mathrm{T}$ cells by siRNA reduced Th2 differentiation ${ }^{36}$, the difference between our result and the report may be attributed to different methods or species we used. We also confirmed that there was the normal differentiation of Th17 cells in Thpok ${ }^{\text {Cre }} S a t b 1^{\mathrm{fl} / \mathrm{fl}}$ mice immunized with $\mathrm{MOG}_{35-55}$ peptide emulsified in complete Freund's adjuvant (CFA) (Fig. 1f). Collectively, these results indicate that Satb1 is dispensable for the differentiation of Th17 cells in vivo and for the induction of the Th17 subset in vitro.

Satb1 regulates the pathogenic function of Th17 cells in EAE. We next investigated the role of Satb1 in the effector functions of Th17 cells in EAE, an animal model of multiple sclerosis ${ }^{37,38}$. To determine if Satb1 had a specific role in Th17 cells at the effector phase, we crossed Satb $1^{\mathrm{fl} / \mathrm{fl}}$ mice with $\mathrm{Ill} / \mathrm{a} \mathrm{Cre}^{\mathrm{Cre}} \mathrm{R} 26 \mathrm{R}^{\mathrm{eYFP}}$ mice to generate $I l 17 a^{\mathrm{Cre}} R 26 R^{\mathrm{eYFP}}$ Satb $1^{\mathrm{f} / \mathrm{fl}}$ conditional knockout mice, in which Cre-mediated deletion of Satb1 occurs in Th17 cells upon their differentiation into IL-17-expressing $\mathrm{eYFP}^{+} \mathrm{CD}^{+}$ $\mathrm{T}$ cells. We refer to these mice as Th17 $7^{\text {Satb } 1 \mathrm{KO}}$ henceforth. We immunized them with $\mathrm{MOG}_{35-55}$ peptide in $\mathrm{CFA}$ to induce $\mathrm{EAE}^{35}, 39$. Notably, Th17 Satb1KO mice were resistant to the development of EAE with fewer eYFP ${ }^{+}$Th17 cells infiltrating the spinal cord compared with control (Il17aCre $\left.R 26 R^{\mathrm{eYFP}} S a t b 1^{\mathrm{wt} / \mathrm{wt}}\right)$ mice (Fig. 2a-c and Table 1). To examine any defects in the effector functions of Th17 cells lacking Satb1, we analyzed the migration and production of cytokines by Th17 cells from Th17Satb1KO and control mice with the same clinical score. Consistent with the normal development of Th17 cells in the absence of Satb1 expression (Fig. 1), the loss of Satb1 did not significantly affect the differentiation or expansion of Th17 cells in the draining LNs and the migration of Th17 cells into the spinal cord with the same EAE clinical score (Fig. 2d, e). Th17 cells lacking Satb1 expressed IFN- $\gamma$, IL-2, and IL-17 at levels similar to control cells, but showed impaired production of GMCSF, a key pathogenic cytokine of the disease ${ }^{18,19}$ (Fig. 2f). Defective secretion of GM-CSF in Satb1-deficient Th17 cells was confirmed by re-stimulation with an anti-CD3 monoclonal antibody (Fig. $2 \mathrm{~g}$ and Supplementary Fig. $6 \mathrm{~b}$ for gating strategies). IL-10, a hallmark of non-pathogenic Th17 cells ${ }^{17}, 40,41$, was not secreted by control or Satb1-deficient Th17 cells, even upon anti$\mathrm{CD} 3$ re-stimulation (Fig. 2f, g).

Th17 cells from the draining LNs of control EAE mice had significantly higher levels of Satbl than those from the PPs

Fig. 1 Normal development of non-pathogenic Th17 cells from Satb1-deficient T cells. a qPCR of $C D 4^{+} C D 8^{+}(D P), C^{+} 4^{+} C D 8^{-}(C D 4 S P)$, and $C D 4^{-} C D 8^{+}$ (CD8SP) thymocytes and CD8 ${ }^{+}, \mathrm{CD} 25^{-} \mathrm{CD} 44^{\text {low }} \mathrm{CD} 4^{+}, \mathrm{CD} 25^{\text {high }} \mathrm{CD} 4^{+}, \mathrm{CD} 25^{-} \mathrm{CD} 44^{\text {high }} \mathrm{CD} 4^{+}$, and PPs eYFP+ CD4+ ${ }^{+}$cells for Satb1 mRNA expression. $\mathbf{b}$ Numbers of DP, CD4SP, and CD8SP cells in the thymus of 4-week-old Thpok ${ }^{\text {Cre }}$ Satb fl/fl and Thpok ${ }^{\text {Cre }}$ Satb7wt/wt littermate controls. c Flow cytometry of CD4 + T cells from the LNs and PPs of ThpokCre Satb7wt/wt and Thpok Cre Satbfl//fl mice for intracellular IL-17 expression. The frequencies of IL$17^{+}$in $\mathrm{CD} 4^{+} \mathrm{T}$ cells are shown. d Flow cytometry of splenic CD4+ $4^{+}$cells for intracellular IL-17 and IFN- $\gamma$ expression. The frequencies of IL-17+ and IFN- $\gamma^{+}$

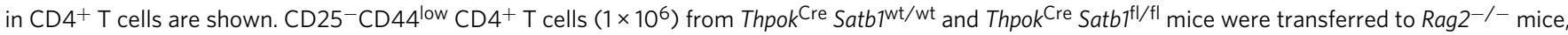

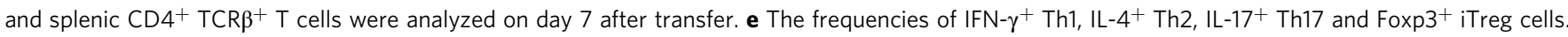
CD25-CD44low CD4+ T cells from ThpokCreSatb7wt/wt and ThpokCreSatb $7^{\mathrm{fl} / \mathrm{fl} l}$ mice were cultured under Th1, Th2, Th17, and iTreg conditions for 3 days. Each symbol represents an individual mouse, and the horizontal lines indicate the mean values. $\mathbf{f}$ Flow cytometry of CD4 ${ }^{+} \mathrm{T}$ cells from the draining LNs of Thpok ${ }^{C r e}$ Satb $7^{\mathrm{wt} / \mathrm{wt}}$ and Thpok ${ }^{\mathrm{Cre}}$ Satb $\mathrm{fl}^{\mathrm{fl} / \mathrm{fl}}$ mice immunized with MOG-CFA, staining for CD4 and intracellular IL-17 on day 7 after immunization. The frequencies of IL-17+ in CD4 + T cells are shown. The bar graphs $(\mathbf{a}-\mathbf{d}, \mathbf{f})$ show the mean $\pm \mathrm{s} . \mathrm{d} .(n=3)$. The results are representative of three independent experiments (a-f). ${ }^{\star} P<0.05,{ }^{\star \star \star} P<0.0001$ (two-tailed unpaired Student's $t$-test) 
a

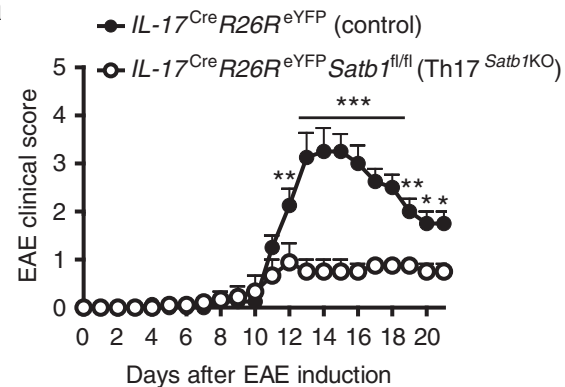

b

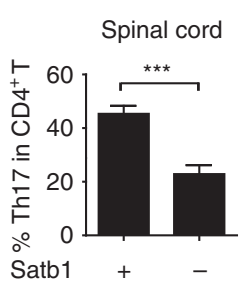

C

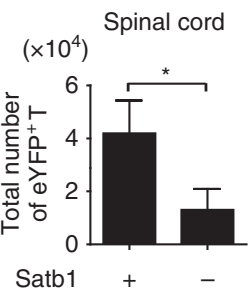

d

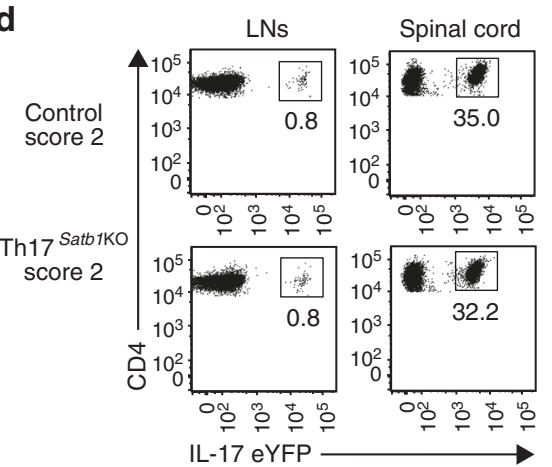

e

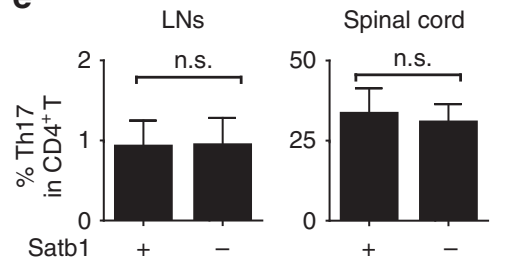

$\left(\times 10^{3}\right)$ Spinal cord

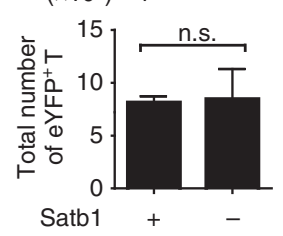

f
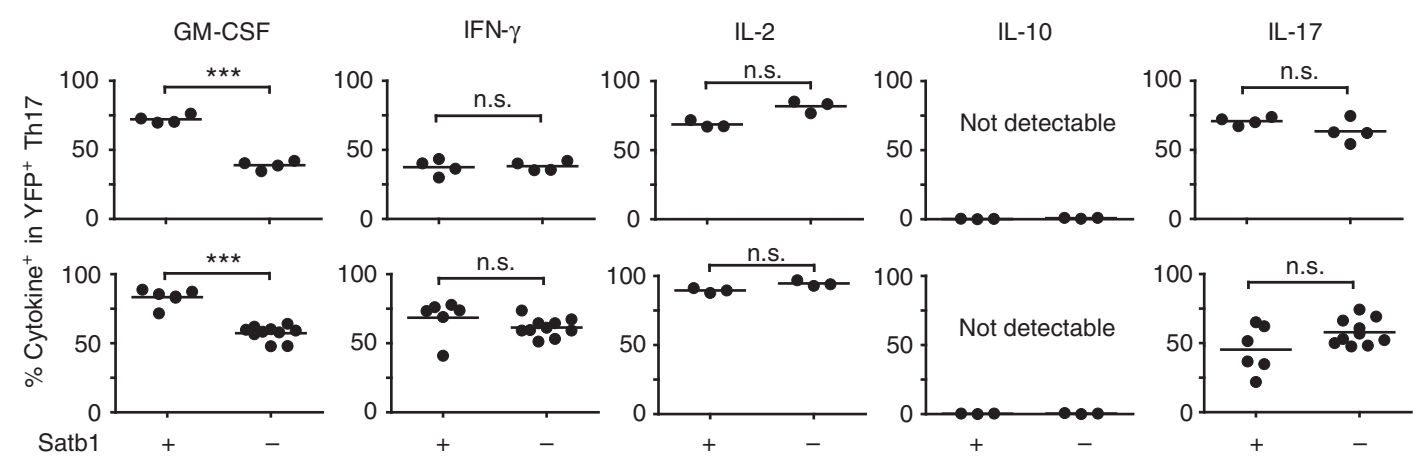

g

GM-CSF
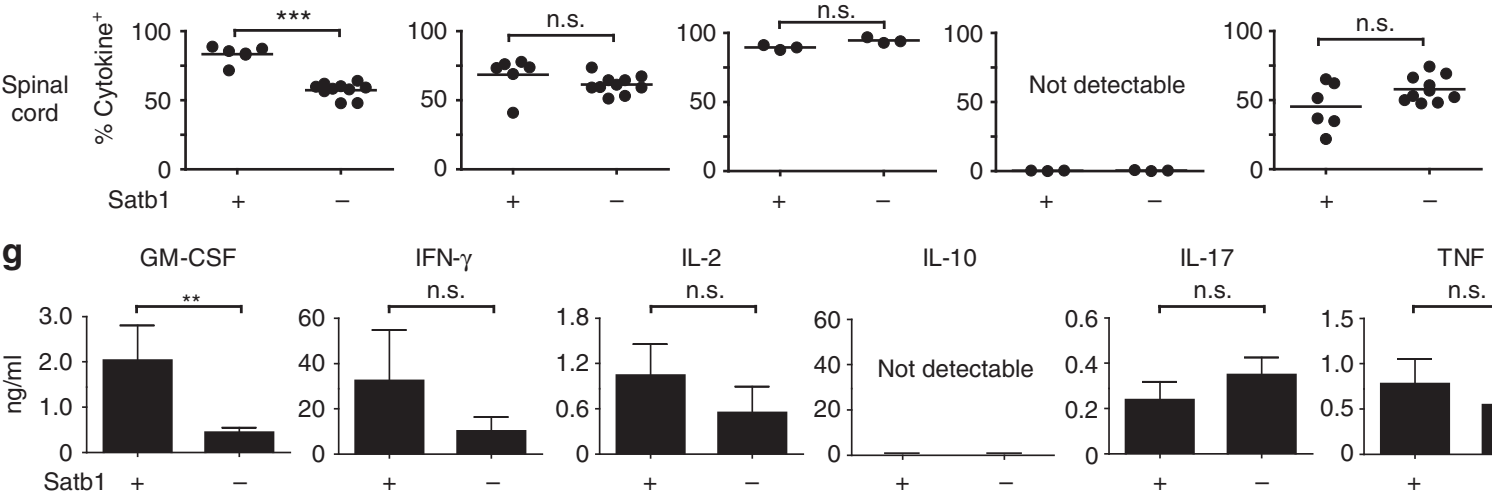

i
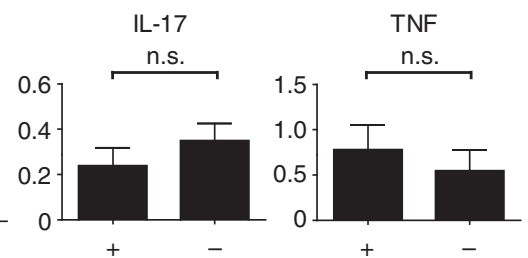

h
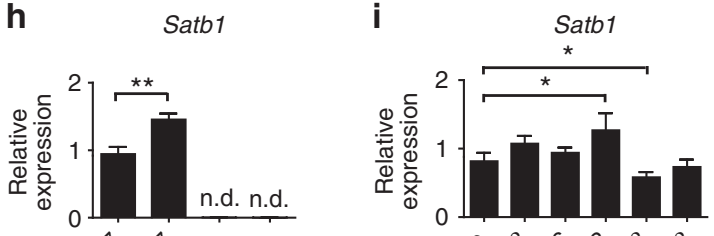

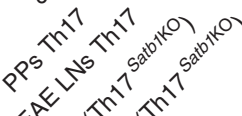

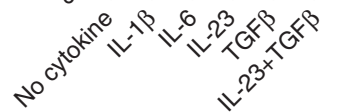

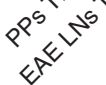

(Fig. 2h). In vitro re-stimulation of draining LN Th17 cells from control EAE mice with IL-23, but not IL-1 $\beta$ and IL-6 increased Satbl expression, whereas TGF- $\beta$ restrained its effect, consistent with the previous report ${ }^{42}$ (Fig. 2i).
Collectively, these results suggest that Satb1 does not affect the maintenance and migratory capacity of Th17 cells to inflamed tissues, but Satb1 expression is increased upon IL-23 stimulation and plays a pivotal role in the pathogenicity of EAE and effector 
Fig. 2 Regulation of pathogenic Th17 functions by Satb1. a The mean (+s.e.m.) clinical scores at the days after EAE was induced in I/17aCre $R 26 R$ eYFP

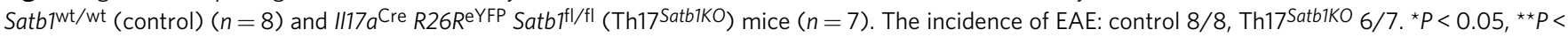
$0.001,{ }^{\star \star \star} P<0.0001$ (two-way ANOVA with Bonferroni's post-test). b, c Percentages and absolute numbers of eYFP + Th17 cells in the spinal cord of control and Th17Satb1KO mice with mean maximal scores of EAE at the peak of the disease ( $14 \pm 3$ days after EAE induction). d Flow cytometry of eYFP expression in $\mathrm{CD}_{4}^{+} \mathrm{T}$ cells from the draining LNs on day 10 and from the spinal cord of the mice showing the same EAE clinical score of 2 at the peak of the disease (on day 17 after EAE induction). e The frequencies and the total numbers of eYFP+ in CD4+ T cells as in $(\mathbf{d})(n=3)$. $\mathbf{f}$ The frequencies of GM$\mathrm{CSF}^{+}, \mathrm{IFN}-\gamma^{+}, \mathrm{IL}-2^{+}, \mathrm{IL}-10^{+}$, and $\mathrm{IL}-17^{+}$in $\mathrm{eYFP}+\mathrm{CD} 4^{+} \mathrm{T}$ cells as in (d). Each symbol represents an individual mouse. The horizontal bars indicate the means. $\mathbf{g}$ Cytokine concentrations in the culture supernatant of re-stimulated Th17 cells are shown. eYFP + Th17 cells were sorted from the spinal cord of control or Th17Satb1KO mice at the peak of EAE. Sorted Th17 cells were re-stimulated with plate-coated anti-CD3 for $24 \mathrm{~h}$. $\mathbf{h}$ qPCR of Satb1 mRNA expression in eYFP+ CD4 + T from PPs and draining LNs at day 7 after EAE induction. i qPCR of Satb1 mRNA expression in eYFP+ Th17 from the draining LNs of EAE mice on day 7 after re-stimulation with CD3/CD28 Dynabeads in the presence of the indicated cytokines for $24 \mathrm{~h}$. The bar graphs (b, $\mathbf{c}, \mathbf{e}, \mathbf{g}-\mathbf{i})$ show the mean \pm s.d. $(n=3)$. The results are representative of at least three independent experiments $(\mathbf{a}-\mathbf{i}) .{ }^{\star} P<0.05,{ }^{\star \star} P<0.001,{ }^{\star \star \star} P<0.0001$ (two-tailed unpaired Student's t-test)

Table 1 Clinical courses of control and Th175atb1KO mice after EAE induction

\begin{tabular}{|c|c|c|c|}
\hline & Control $(n=8)$ & Th17 ${ }^{\text {Satb1KO }}(n=7)$ & \\
\hline Mean maximal score & $3.625 \pm 0.744$ & $1.000 \pm 0.534$ & $P<0.0001$ \\
\hline Mean day of onset & $11.13 \pm 1.885$ & $13.0 \pm 2.517$ & n.s. \\
\hline
\end{tabular}

a
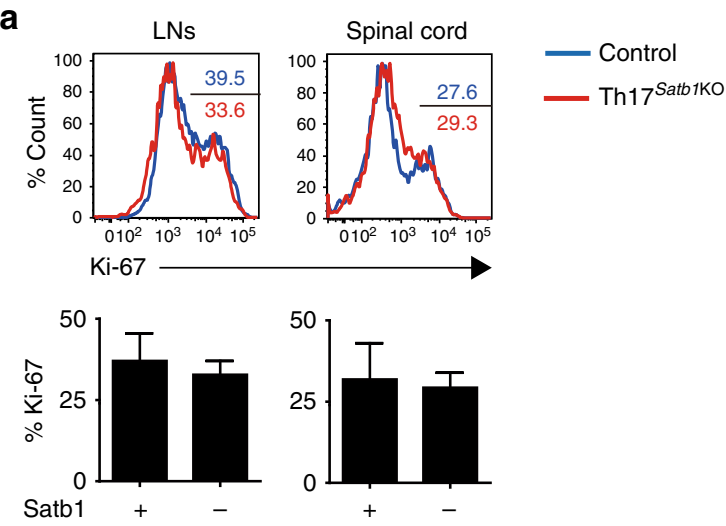

C

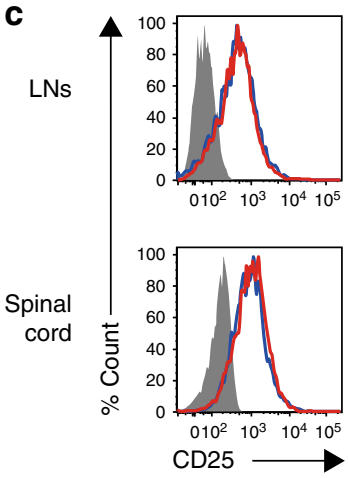

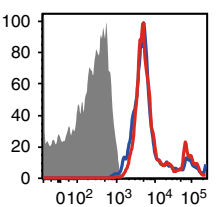
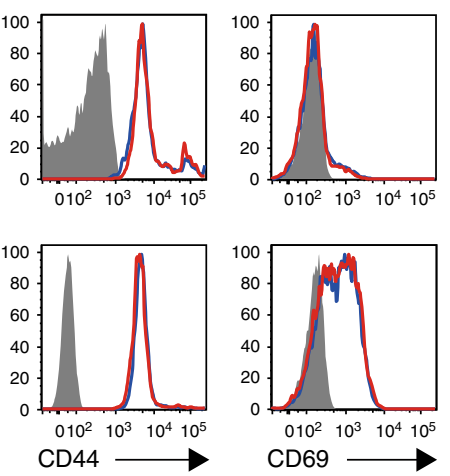

b
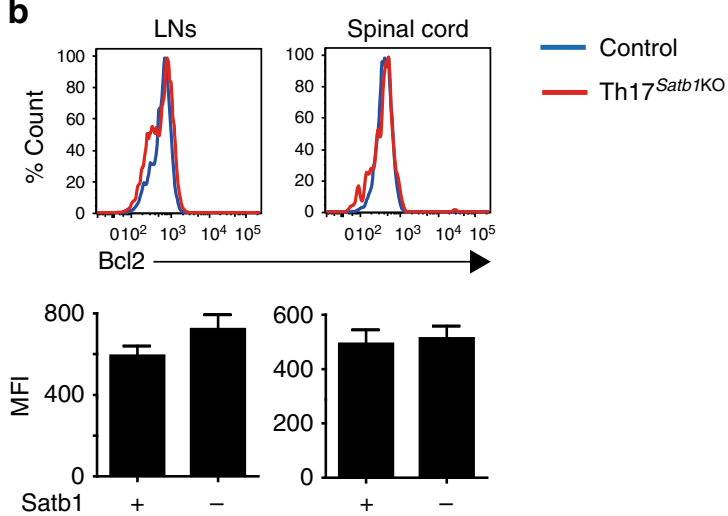
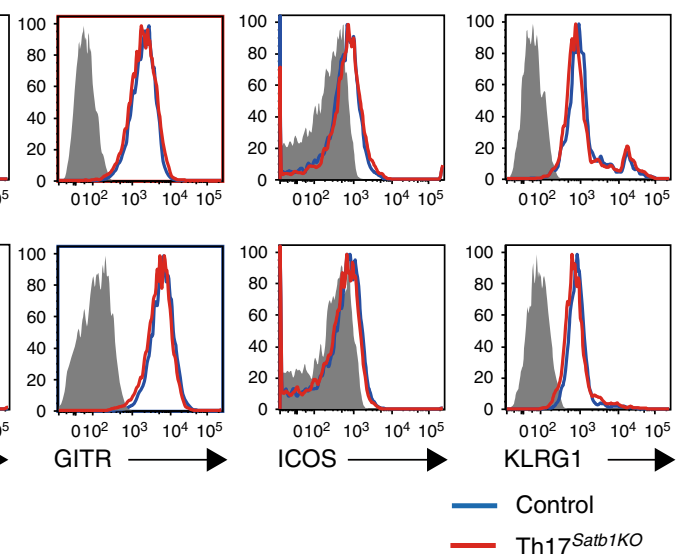

Fig. 3 Comparable activation status between control and Satb1-deficient Th17 cells. Flow cytometry of eYFP ${ }^{+} \mathrm{CD}^{+}{ }^{+} \mathrm{T}$ cells from the draining LNs and the spinal cord for the expression of Ki-67 (a), Bcl-2 (b), and CD25, CD44, CD69, CD103, GITR, ICOS, and KLRG1 (c) as in Fig. 2d. The frequencies of Ki-67+ (a) and the mean fluorescence intensity (MFI) of Bcl-2+ in eYFP ${ }^{+} \mathrm{CD} 4^{+} \mathrm{T}$ cells $(\mathbf{b})$ are shown. The bar graphs $(\mathbf{a}$ and $\mathbf{b})$ show the mean $\pm \mathrm{s} . \mathrm{d}$. $(n=3)$. The results are representative of at least three independent experiments $(\mathbf{a}-\mathbf{c})$ 
$\mathbf{a}$
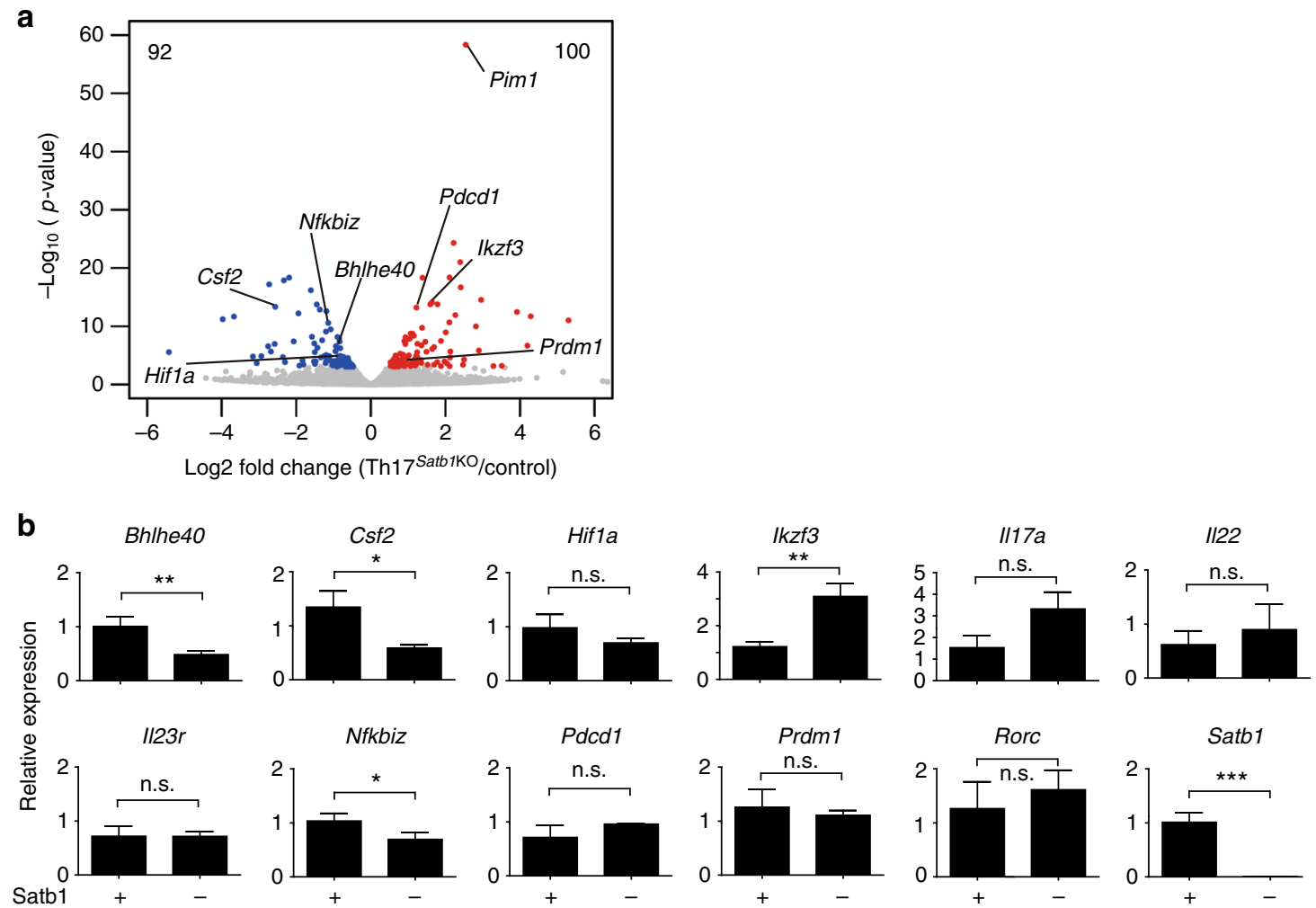

C
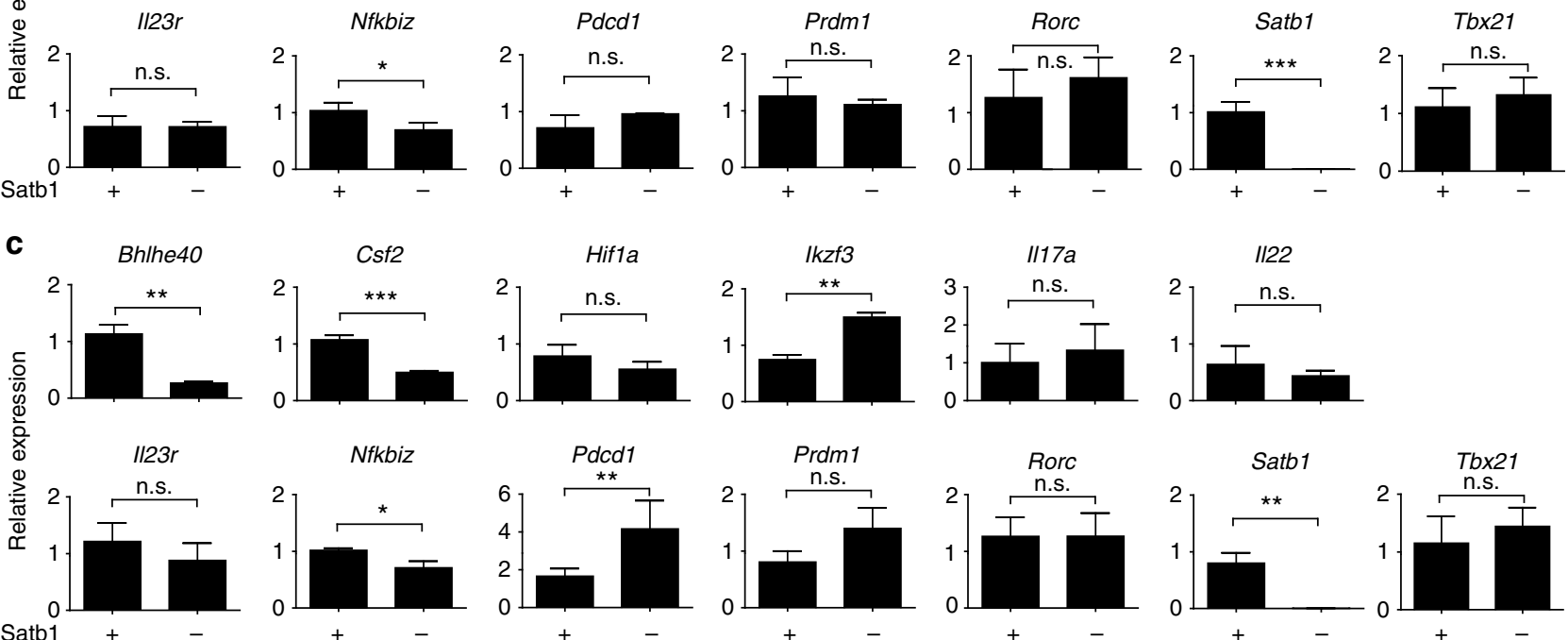

d
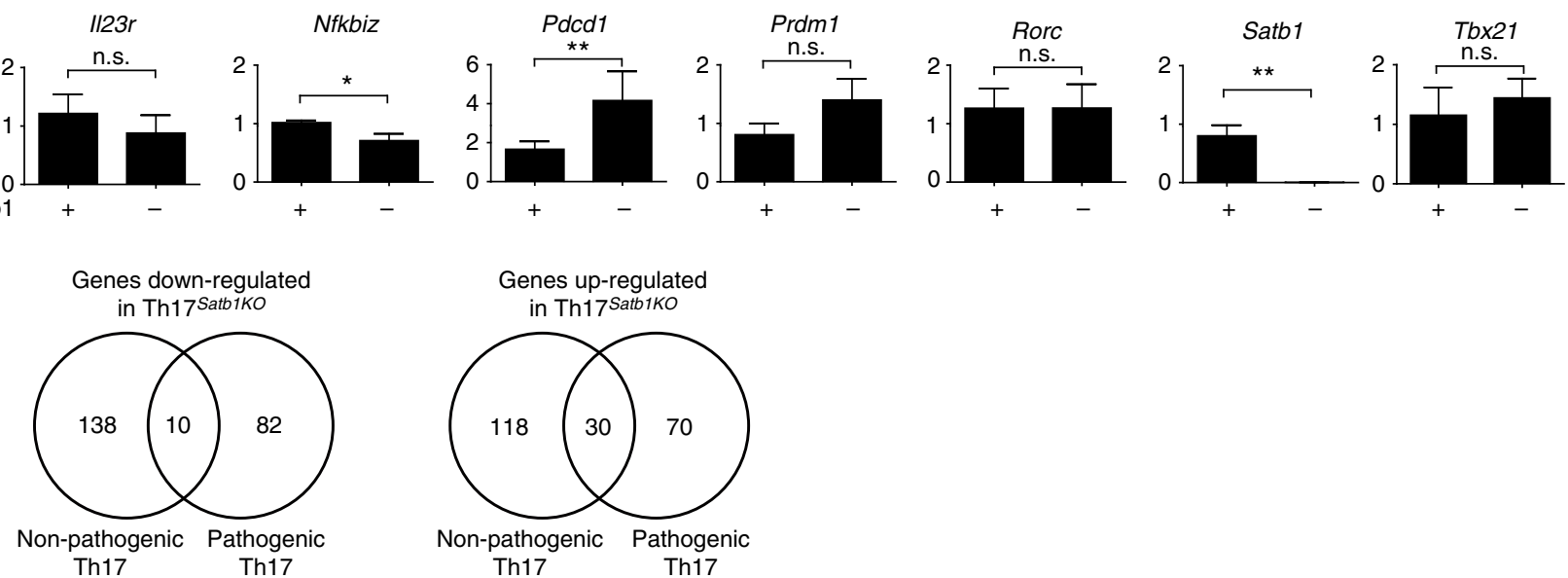

Fig. 4 Differential gene expression in pathogenic and non-pathogenic Th17 cells from control and Th17Satb1kO mice. a RNA-seq analysis of eYFP + CD4 ${ }^{+}$ T cells from the spinal cord of control and Th17Satb1KO mice after EAE induction. eYFP ${ }^{+}$Th17 cells were sorted at the peak of the disease (14 days after EAE induction). The volcano plot shows the differential gene expression between the Th17Satb1KO versus control eYFP $+\mathrm{CD}^{+}{ }^{+} \mathrm{T}$ cells. The genes up-regulated in $\mathrm{Th}_{17}$ Satb1KO $\mathrm{eYFP}^{+} \mathrm{CD}^{+} \mathrm{T}$ cells are shown in red, and the genes down-regulated are shown in blue. Two biological replicates were analyzed. $\mathbf{b}$, $\mathbf{c}$ aPCR of eYFP+ CD4+ T cells from the draining LNs (b) and spinal cord (c) as in (a) for the expression of Bhlhe40, Csf2, Hifla, Ikzf3, II17a, II22, II23r, Nfkbiz, Pdcd1, Prdm1, Rorc, Satb1, and Tbx21. eYFP+ Th17 cells from the draining LNs were sorted on days 7-14 after EAE induction, and eYFP+ Th17 cells from spinal cord was sorted at the peak of the disease ( $14 \pm 3$ days after EAE induction). d Venn diagram presenting overlap of the number of down-regulated or upregulated genes between $\mathrm{PP}$ eYFP ${ }^{+} \mathrm{CD}^{+} \mathrm{T}$ cells (non-pathogenic) and eYFP $\mathrm{CD}^{+} \mathrm{T}$ cells (pathogenic) from the inflamed spinal cord of Th17 SatbikO mice after EAE induction. eYFP+ Th17 cells were sorted at the peak of the disease (14 days after EAE induction). The bar graphs (b and $\mathbf{c}$ ) show the mean \pm s.d. $(n=3) .{ }^{\star} P<0.05,{ }^{\star \star} P<0.001,{ }^{\star \star \star} P<0.0001$ (two-tailed unpaired Student's $t$-test) 


\section{Table 2 The list of the overlapped genes shown in Fig. 4d}

\begin{tabular}{ll} 
10 Down-regulated genes & 30 Up-regulated genes \\
\hline 5430421N21Rik & A930015D03Rik \\
Ccr7 & Aplp2 \\
Cd9 & C920025E04Rik \\
Galnt9 & Cd226 \\
Lrig1 & Ddx28 \\
Mocs1 & Dkk3 \\
St8sia1 & F2r \\
Tbc1d4 & Glo1 \\
Tgfbr3 & Gpx1 \\
Tnfsf11 & Gzma \\
& H2-T10 \\
& H2-T24 \\
& Hlf \\
& Ifi203 \\
& Il10ra \\
& Lrrn3 \\
& Pim1 \\
& Plek \\
& Plekhf1 \\
& Plxdc2 \\
& Ppp1r14c \\
& Prdm1 \\
& Rbm24 \\
& Sept11 \\
Slc25a24 \\
Stom \\
Tns4 \\
Tubb5 \\
Uhrf2 \\
Zfand6 \\
\end{tabular}

The list of the overlapped genes down-regulated or up-regulated between non-pathogenic (PP eYFP+ $\left.\mathrm{CD}^{+}\right)$Th17 cells and pathogenic $\left(\mathrm{YYFP}^{+} \mathrm{CD}^{+}\right)$Th17 cells from the inflamed spinal cord of Th17SatbiKO mice after EAE induction. EYFP+ Th17 cells were sorted at the peak of the disease (14 days after EAE induction)

functions of Th17 cells by regulation of GM-CSF production. IL$1 \beta$ and IL-6 signaling pathways may interact with Satb1 for the development and function of Th17 cells, but are not involved in the regulation of Satb1.

Satb1 does not affect activation markers in Th17 cells. Given that Satb1 influences the regulation of multiple genes in $\mathrm{T}$ cells and their precursors $29,39,43$, we compared the activation and proliferation profile of eYFP ${ }^{+}$Th17 cells from Th17Satb1KO and control mice after EAE induction. The expression levels of Ki-67 and Bcl-2 in Th17 cells from draining LNs and the spinal cord were comparable between the two mouse strains (Fig. 3a, b). Further, the absence of Satb1 in effector Th17 cells did not affect the expression of surface markers CD25, CD44, CD69, CD103, GITR, ICOS, and KLRG1 (Fig. 3c), indicating that Satb1 does not regulate these activation-, proliferation-, and survival-associated genes in effector Th17 cells.

Satb1 regulates pathogenic gene expression in Th17 cells. Since Satb1-deficient Th17 cells exhibited no changes in the expression of key activation and proliferation markers (Fig. 3), global expression profiling was conducted to identify other dysregulated genes associated with the loss of Satb1. To this end, eYFP ${ }^{+}$Th17 cells were sorted from the spinal cords of Th17SatblKO and control mice at the peak of the disease after EAE induction and were subjected to gene expression analysis by RNA-seq. As shown in Fig. 3, Satb1 deficiency showed limited effect on global gene expression. We identified 192 differentially expressed genes, with
92 down-regulated and 100 up-regulated genes, in Satb1-deficient Th17 cells compared with control Th17 cells (Fig. 4a). Among these, we validated Satb1 and 12 other potential candidates associated with Th17 pathogenicity by q-PCR (Fig. 4b, c). Of the 12 genes, 3 genes (Bhlhe $40, C s f 2$, and Nfkbiz) were significantly down-regulated in Satb1-deficient Th17 cells from both the draining LNs and spinal cord, 1 gene (Ikzf3) was significantly upregulated in Satb1-deficient Th17 cells from both the draining LNs and spinal cord, and 1 gene (Pdcd1) was significantly upregulated in Satb1-deficient Th17 cells from only the spinal cord (Fig. 4c). Csf2 encodes GM-CSF and Bhlhe40 encodes a key transcription factor driving Csf2 transcription ${ }^{44,45}$; therefore, their down-regulation is consistent with the impaired production of GM-CSF by Satb1-deficient Th17 cells (Fig. 2f, g). Nfkbiz encodes a transcriptional coregulator that acts with ROR $\gamma \mathrm{t}$ to regulate IL-17 expression in Th17 cells ${ }^{46}$; the effect was likely to be limited because of the normal development of Th17 cells and IL-17 production in the absence of Satb1. By contrast, the expression of Ikzf3, which promotes the development of Th17 cells by repressing IL-2 production ${ }^{47}$, was significantly higher in Satb1-deficient Th17 cells despite their ability to secrete IL-2 (Fig. 2f). There was no significant difference in the expression of genes encoding Th17 signature cytokines and regulators such as Hifla, Ill7a, Il22, Il23r, Prdm1, and Rorc confirmed by q-PCR (Fig. 4b, c). Notably, the differential regulation of Bhlhe 40 and $P d c d 1$, which encodes the inhibitory receptor PD-1, was not seen in non-pathogenic Th17 cells in PPs, which barely secreted GMCSF (Supplementary Fig. 2a-c). Gene expression analysis revealed that the majority of genes dysregulated in the absence of Satb1 was not overlapped between non-pathogenic and pathogenic Th17 cells. $~ 150$ genes were up-regulated and down-regulated in non-pathogenic Satb1-deficient Th17 cells, but did not affect the signature cytokine Ill7 and Il22 expression and transcription factors including Bhlhe 40 (Fig. 4d and Supplementary Fig. 2d). The specific role of the overlapped genes ( 10 down-regulated and 30 up-regulated) in other immune reactions remains to be defined in the future study (Table 2). Taken together, these results indicate that Satb1 specifically regulates the divergent gene expression in non-pathogenic and pathogenic Th17 cells at different locations under homeostatic and inflammatory conditions.

Bhlhe40 restores the pathogenicity of Satb1 $1^{-I-}$ Th17 cells. We next focused on Bhlhe40 as a possible regulatory factor of Satb1mediated GM-CSF production. The expression of Bhlhe 40 was higher in pathogenic Th17 cells from the draining LNs of control EAE mice than in non-pathogenic Th17 cells from PPs and CD25 ${ }^{-} \mathrm{CD} 44^{\text {high }} \mathrm{CD}^{+}$effector T cells (Fig. 5a), correlating with the increased expression of Satb1 in Th17 cells from the draining LNs of control EAE mice (Fig. 2h). To examine the function of Bhlhe40 in Satb1-deficient Th17 cells in which Bhlhe40 expression was decreased, we constructed a retroviral vector to ectopically express Bhlhe 40 and NGFR as a reporter gene and validated the induction of Bhlhe40 in $\mathrm{NGFR}^{+} \mathrm{T}$ cells after Bhlhe40 was transduced in naive $\mathrm{CD} 4^{+} \mathrm{T}$ cells under Th0 conditions (Fig. $5 \mathrm{~b}$ ). We then addressed whether the Satb1-Bhlhe40 axis plays a critical role in the pathogenesis of Th17 cells. Retroviral transduction of a Bhlhe40-expressing vector into Satb1-deficient CD4 ${ }^{+}$ $\mathrm{T}$ cells, followed by adoptive transfer into Rag $2^{-I-}$ mice in which EAE was induced 2 weeks later, substantially restored the pathogenic function of Satb1-deficient $\mathrm{CD} 4^{+} \mathrm{T}$ cells (Fig. $5 \mathrm{c}$ and Supplementary Fig. 6d for gating strategies), as well as GM-CSF expression in the draining LNs (Fig. 5d) and spinal cord (Fig. 5e) of EAE recipient mice. Collectively, these results indicate that Satb1 regulates the pathogenic function of Th17 cells and GMCSF production in part via Bhlhe40. 
a

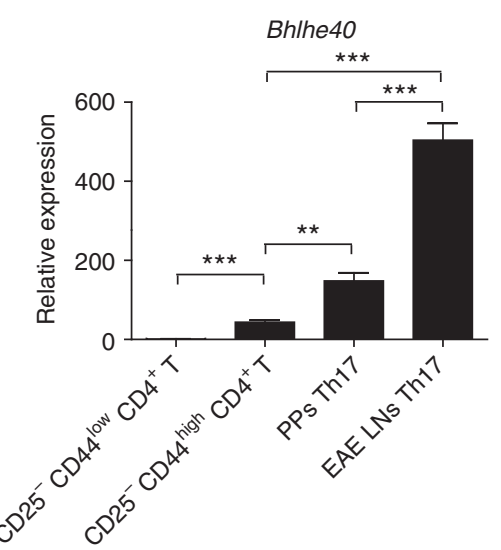

C

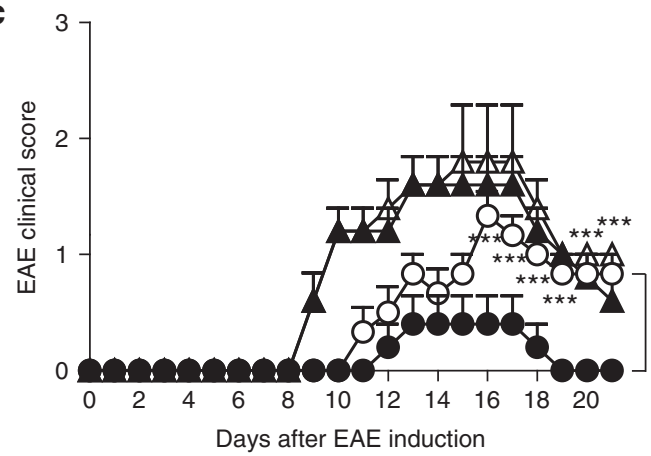

d
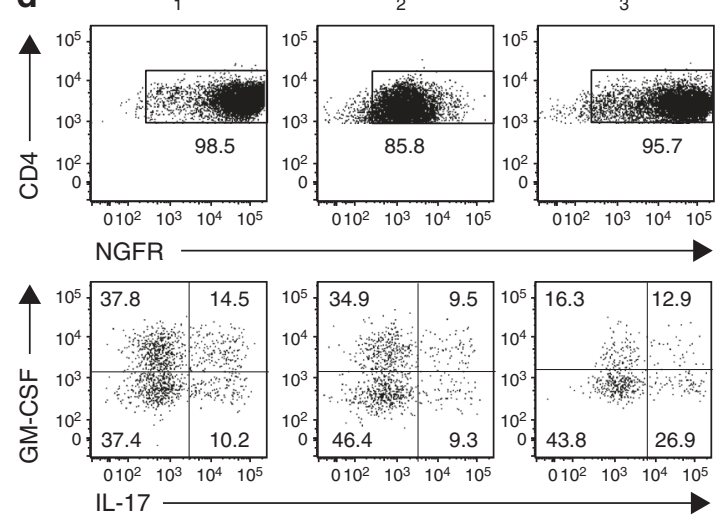

e
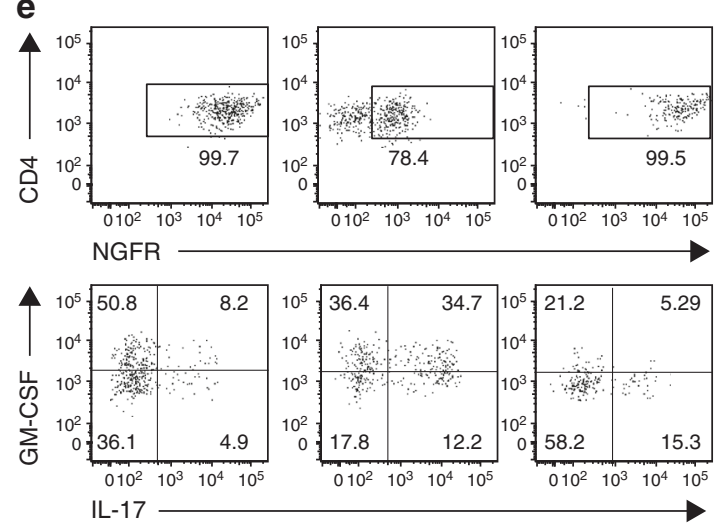

Satb1 inhibits PD-1 expression in effector Th17 cells. In an attempt to characterize the impaired effector functions of Th17 cells in the absence of Satb1, we found that the production of GM-CSF, IFN- $\gamma$, IL-2, and TNF, but not IL-17, was greatly impaired when Satb1-deficient Th17 cells from the inflamed

\section{Bhlhe40}

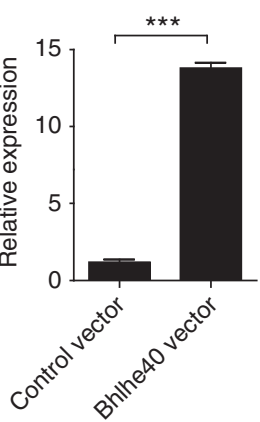

$\Delta$ Control $C D 4^{+} T$ cells + Bhlhe40 vector

- Control $\mathrm{CD}_{4}{ }^{+} \mathrm{T}$ cells + control vector

- Th17 ${ }^{\text {Satb1KO }} \mathrm{CD}^{+} \mathrm{T}$ cells + Bhlhe40 vector

- Th17 ${ }^{\text {Satb1KO }} \mathrm{CD}^{+} \mathrm{T}$ cells + control vector
1) Control $C D 4^{+} T$ cells + control vector

2) $\mathrm{Th} 17^{\text {Satb1KO }} \mathrm{CD}^{+} \mathrm{T}$ cells + Bhlhe40 vector

3) $\mathrm{Th} 17^{\text {SatbiKO }} \mathrm{CD}^{+} \mathrm{T}$ cells + control vector
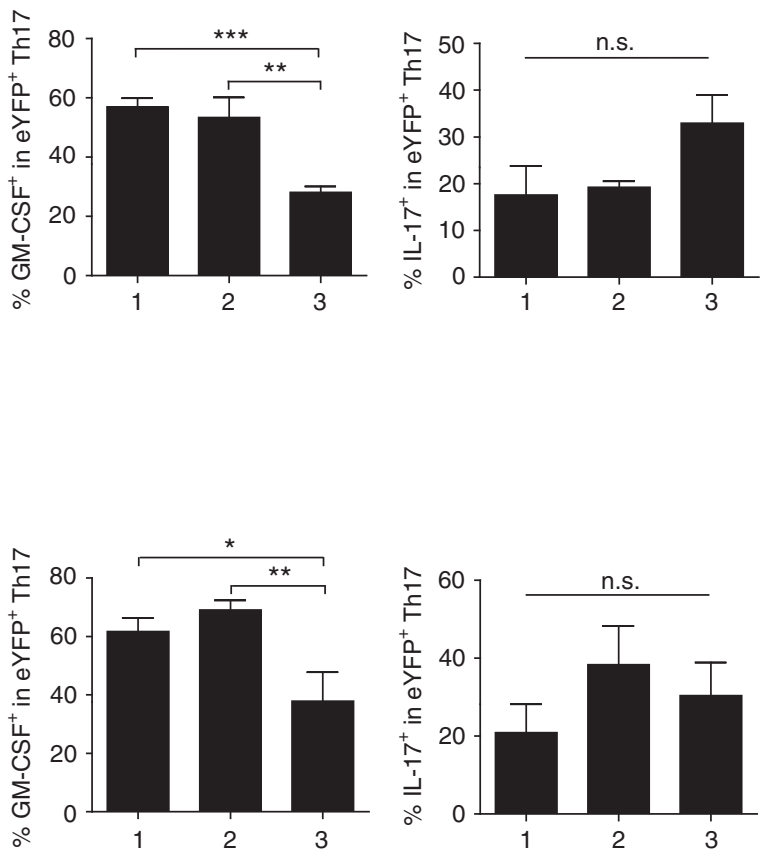

spinal cord of Th17 ${ }^{\text {SatblKO }}$ mice were cultured with bone marrow-derived dendritic cells (BMDCs) in the presence of MOG $_{35-55}$ peptide while GM-CSF and IL-2 were also affected in Satb1-deficient Th17 cells from the spleen (Fig. 6a and Supplementary Fig. 3a). Since the production of IFN- $\gamma$, IL-2, and TNF 
Fig. 5 Retroviral transduction of Bhlhe40 restores the pathogenic function of Satb1-deficient Th17 cells. a qPCR of Bhlhe40 mRNA expression in CD25-

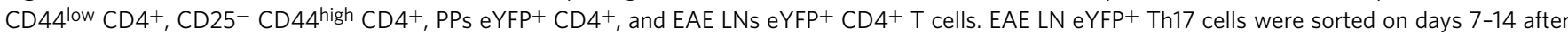
EAE induction. $\mathbf{b}$ qPCR of Bhlhe40 mRNA expression 3 days after Bhlhe40 was retrovirally transduced in naive CD25-CD44low CD4+ T cells. c Mean ( $+\mathrm{s}$. e.m.) clinical scores on the days after EAE induction in Rag2 ${ }^{-/}$- mice; the following conditions were followed for the transfer of NGFR + CD4 $+\mathrm{T}$ cells $(2 \times$ $\left.10^{6}\right)$ : (1) control CD4 ${ }^{+}$T cells transduced with the Bhlhe40 vector $(n=5),(2)$ control CD4 ${ }^{+}$T cells transduced with the control vector $(n=5)$, $(3)$ Th17Satb1KO CD4 + T cells transduced with the Bhlhe40 vector $(n=6)$, and (4) Th17Satb1KO CD4 ${ }^{+}$T cells transduced with the control vector $(n=5)$. The incidence of EAE was as follows: (1) 5/5, (2) 5/5, (3) 6/6, and (4) 2/5. ${ }^{* \star} P<0.0001$ (two-way ANOVA with Bonferroni's post-test). d, e Flow cytometry of $\mathrm{CD}^{+}{ }^{+} \mathrm{T}$ cells (top) and NGFR ${ }^{+}$eYFP ${ }^{+} \mathrm{CD} 4^{+} \mathrm{T}$ cells (bottom) in draining LNs (d) and spinal cord (e) as in (c) for IL-17 and GM-CSF expression on day 14 after EAE inductions. The frequencies of $\mathrm{GM}-\mathrm{CSF}^{+}$in eYFP $+\mathrm{CD} 4^{+}$T cells are shown. The bar graphs $(\mathbf{a}, \mathbf{b}, \mathbf{d}, \mathbf{e})$ show the mean $\pm \mathrm{s} . \mathrm{d}$. $(n=3)$. The results are representative of two independent experiments. ${ }^{\star \star} P<0.001 ;{ }^{\star \star \star} P<0.0001$ (two-tailed unpaired Student's $t$-test or one-way ANOVA)

upon re-stimulation with anti-CD3 was comparable between Satb1-deficient and control Th17 cells (Fig. 2g), and the communication between dendritic cells and $\mathrm{T}$ cells is based on receptor-ligand interactions that regulate immune checkpoints, BMDC-mediated suppression of effector cytokines prompted us to investigate the expression of immune checkpoint molecules by Th17 cells ${ }^{48}$. Satb1-deficient Th17 cells from the inflamed spinal cord, but not the draining LNs and spleen of EAE mice, expressed higher levels of PD-1 than control Th17 cells in accordance with the up-regulation of $P d c d-1$ observed in Satb1-deficient Th17 cells and the similar finding reported in activated $\mathrm{T}$ cells ${ }^{42}$ (Fig. $4 \mathrm{~b}, \mathrm{c}$ and $6 \mathrm{~b}, \mathrm{c}$ and Supplementary Fig. $3 \mathrm{~b}$ ). The expression of other immune checkpoint molecules, such as CTLA-4, LAG3, TIGIT, and Tim3, was unchanged in Satb1-deficient Th17 cells from the spinal cord, draining LNs and spleen (Fig. 6b and Supplementary Fig. 3b).

We next examined whether the up-regulation of PD-1 by Satb1-deficient Th17 cells is related to the decreased severity of EAE seen in Th17 ${ }^{\text {Satb1KO }}$ mice (Fig. 2a). To this end, anti-PD-1 blocking monoclonal antibody was administered to mice following EAE induction. Th17 Satb1KO mice that received the anti-PD-1 antibody exhibited increased severity of disease compared to Th17Satb1KO mice that received the isotypematched control antibody. Disease severity in control mice was comparable between anti-PD-1 and control antibody-treated mice (Fig. 6d). Moreover, when Th17 cells from control or Th17 SatbIKO inflamed spinal cords were co-cultured with BMDCs in the presence of $\mathrm{MOG}_{35-55}$ peptide and the anti-PD-1 antibody, the production of IL-2 and IL-17 by control or Satb1-deficient Th17 cells was significantly enhanced, whereas the production of GM-CSF, IFN- $\gamma$, IL-1 $\beta$, IL-6, IL-23, and TNF was unaffected by the presence of the anti-PD-1 antibody (Fig. 6e and Supplementary Fig. 3c), indicating that $\mathrm{PD}-1$ signaling predominantly regulates IL-2 and IL-17 production, but not all the effector cytokines including GM-CSF, which appears to be regulated by Bhlhe40 in Th17 cells. Taken together, these results indicate that Satb1-mediated regulation of PD-1 expression controls specific effector cytokines including IL-17 by Th17 cells and contributes to the pathogenesis of EAE.

Satb1 binds to the promoter region at the Bhlhe40 locus. To gain further insight into Satb1-dependent transcriptional regulation in Th17 cells, we investigated genome-wide Satb1-binding sites in Th17 cells using chromatin immunoprecipitation sequencing (ChIP-seq) analyses with an anti-Satb1 monoclonal antibody. In vitro polarized Satb1-deficient $\mathrm{eYFP}^{+}$Th17 cells showed higher levels of PD-1 than control eYFP ${ }^{+}$Th17 cells (Supplementary Fig. 4a), consistent with increased PD-1 expression observed in Th17 cells from the inflamed spinal cords (Fig. 6b). Using eYFP ${ }^{+}$Th17 cells from $I l 17 a^{\mathrm{Cre}} R 26 R^{\mathrm{eYFP}}$ Satb $1^{\text {wt/wt }}$ mice, we analyzed the Satb1 binding sites at affected gene loci in Th17 cells (loci identified in Fig. 4a). Among the gene loci analyzed (Bhlhe40, Pdcd1, Csf2, Hifla, Ikzf3, Nfkbiz, and $\operatorname{Prdm1)}$, Satb1 specifically bound only to the active promoter region of the Bhlhe 40 locus, which was marked by H3K27 acetylation and this association of Satb1 with the enhancer region was also confirmed by quantitative ChIP-PCR (Fig. 7a, b and Supplementary Fig. 4b). However, this active enhancer mark of H3K27ac in Th17 cells could be maintained independently of Satb1. Notably, there was no direct evidence of Satb1 binding on the Pdcd1, Csf2, Hif1a, Ikzf3, Nfkbiz, and Prdm1 loci. These results suggest that there are direct and context-dependent gene regulations by Satb1 that control GM-CSF and PD-1 expression in encephalitogenic tissue Th17 cells, but Satb1 is not involved in the epigenetic modification of the Bhlhe 40 locus.

\section{Discussion}

In this study, we show that the pathogenic effector program, but not the differentiation and non-pathogenic functions of tissue Th17 cells, is specifically controlled by the genome organizer Satb1. Satb1-mediated regulation of Bhlhe40 and PD-1 controls Th17 pathogenicity in part by IL-17 and GM-CSF production in the central nervous system during autoimmune disease. Notably, Satb1 differentially controlled the gene expression profiles in nonpathogenic and pathogenic Th17 cells isolated from the gut and inflamed tissue, respectively. Therefore, Satb1 shaped the divergent gene expression in tissue Th17 cells in an environmental context-dependent manner.

Satb1 regulates a specific set of gene expression in effector Th17 cells under inflammatory conditions. It is well appreciated that Satb1 is regulated by TCR signaling and highly expressed by immature thymocytes and plays a crucial role under physiological conditions in the specification and function of $\mathrm{T}$ cell lineages, including Foxp3 ${ }^{+}$Tregs developed in the thymus, by regulating the chromatin-loop architecture $33,34,46,49$. It is of note that the expression levels of Satb1 are greatly reduced in mature $\mathrm{T}$ cells populating the periphery, implying that peripheral $\mathrm{T}$ cell subsets may decrease the dependency of Satb1 on their functions, and, for instance, its expression in Tregs has little impact on their functions and the Treg-mediated immunological self-tolerance in the periphery $29,32,34,39,49-51$. Although the knockdown of Satb1 reduced IL-17 expression in in vitro-polarized Th17 cells ${ }^{52}$ and the overexpression of SATB1 was observed in patients with anaplastic T lymphoma and increased Th17-associated genes ${ }^{53}$, the role of Satb1 in the differentiation and function of effector Th17 cells in vivo in autoimmune reactions remained elusive. Our results indicate that Satb1 is dispensable for the differentiation and cytokine production of gut Th17 cells, but significantly contributes to inflammatory properties of tissue Th17 cells, consistent with transcriptomic analysis revealing that the absence of Satb1 expression did not affect the fundamental gene expression profile in Th17 cells, unlike immature T cells and its precursors, but specifically controlled a limited number of effector genes in pathogenic Th17 cells in inflamed tissues in EAE mice. 
a
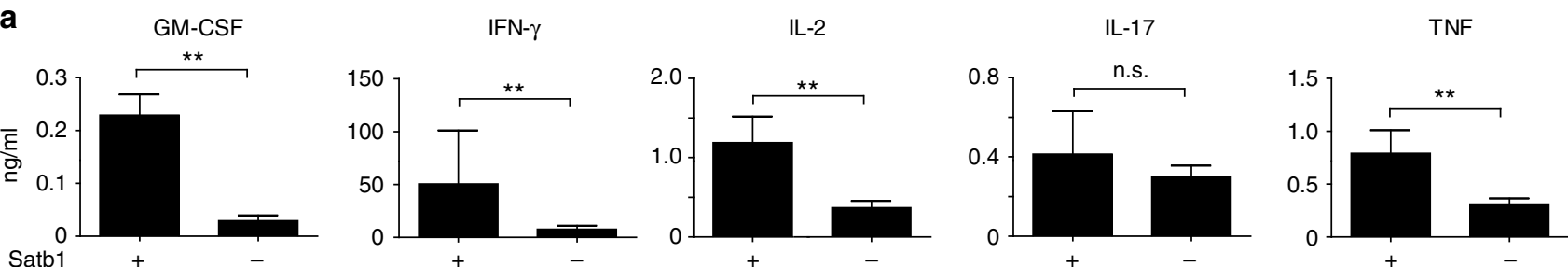

b
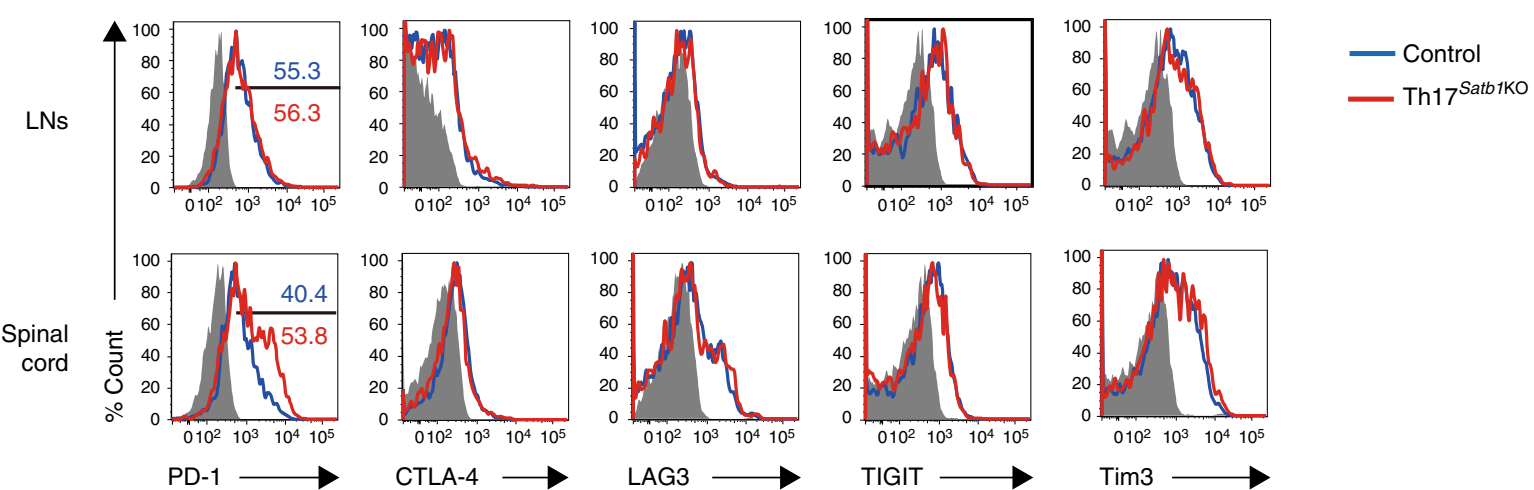

C
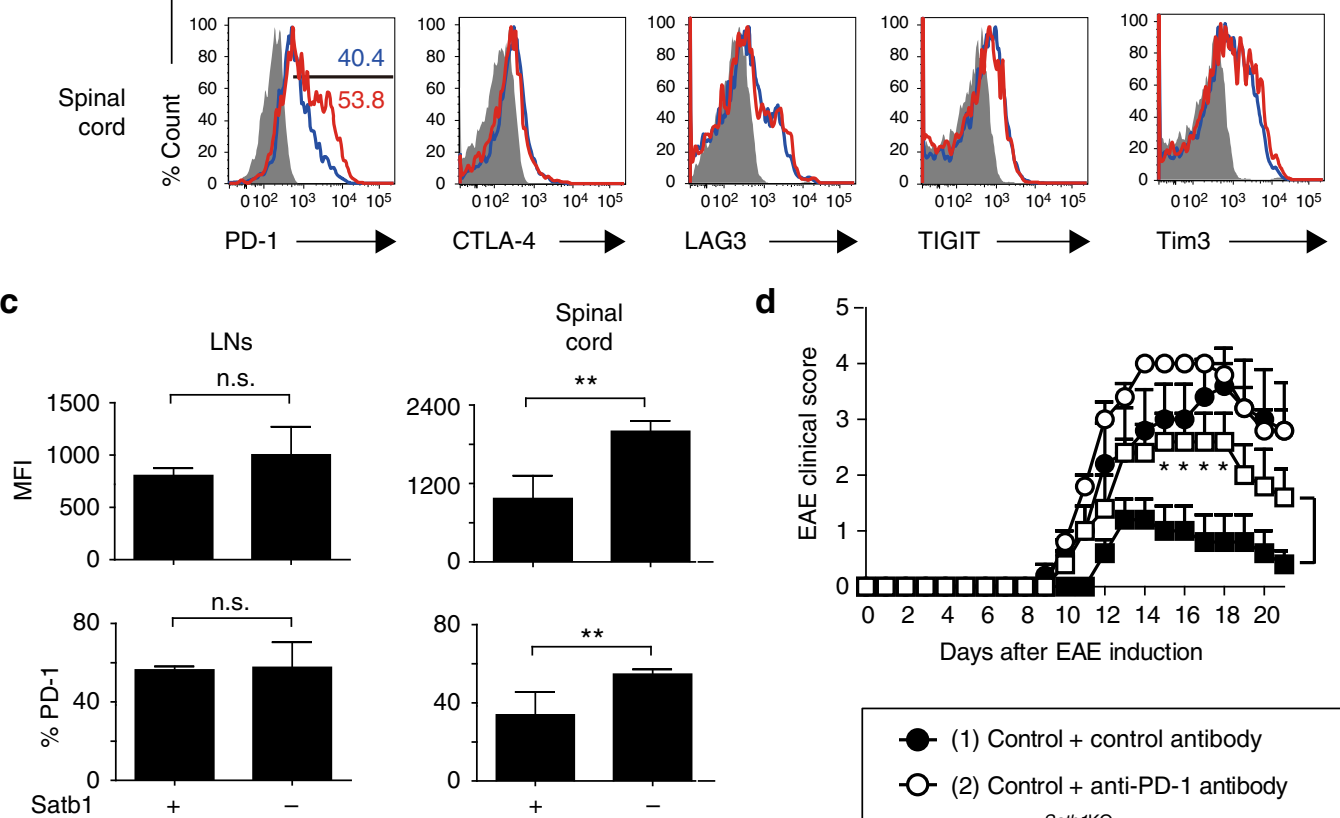

e

GM-CSF
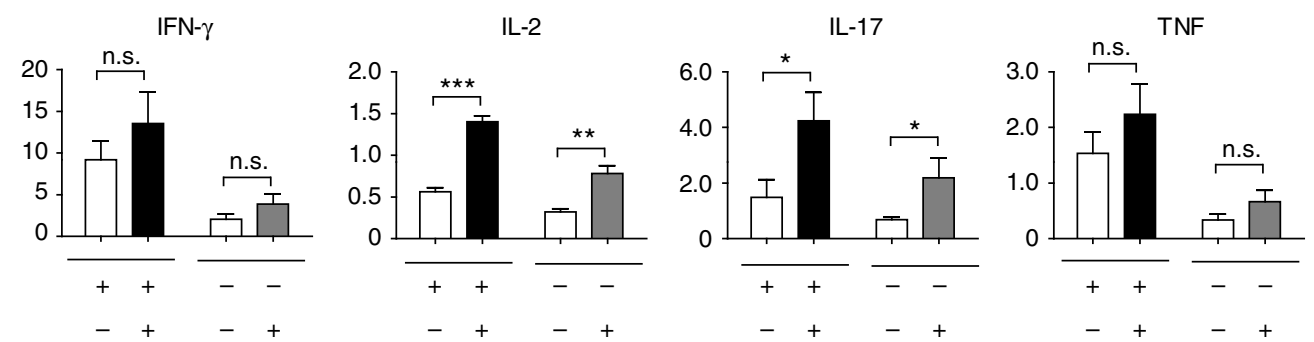

Fig. 6 Satb1 inhibits PD-1 expression by Th17 cells in the spinal cord. a Cytokine concentrations in the culture supernatant of re-stimulated Th17 cells are shown. eYFP ${ }^{+}$Th17 cells were sorted from the spinal cord of control or Th17Satb1KO mice at the peak of EAE. Sorted Th17 cells were re-stimulated with BMDCs in the presence of $M_{30 G}$-55 peptide $(50 \mu \mathrm{g} / \mathrm{ml}$ ) for $24 \mathrm{~h}$. b, c Flow cytometry of draining LNs (day 7 after EAE induction) and spinal cord (day 14 \pm 3 after EAE induction) eYFP+ CD4 + T cells as in Fig. 2d for the expression of PD-1, CTLA-4, LAG3, TIGIT, and Tim3. The frequencies and mean fluorescence intensity (MFI) of PD-1+ in eYFP+ ${ }^{+}{ }^{+} 4^{+}$T cells are shown (c). d The mean (+s.e.m.) clinical scores on the days after EAE was induced in control or Th17 Satb1KO mice, which were treated with the isotype-matched control (IgG2a) or anti-PD-1 mAbs $(n=5)$. The incidence of EAE was as follows: (1) 5/5, (2) 5/5, (3) 4/5, and (4) 5/5. * $P<0.05$ (two-way ANOVA with Bonferroni's post-test). e Cytokine concentrations in the culture supernatant of restimulated Th17 cells are shown. eYFP ${ }^{+}$Th17 cells were sorted from the spinal cord of control or Th17Satb1KO mice at the peak of EAE and then restimulated with BMDCs in the presence of $\mathrm{MOG}_{35-55}$ peptide $(50 \mu \mathrm{g} / \mathrm{ml})$ with or without the PD-1 antibody $(20 \mu \mathrm{g} / \mathrm{ml})$ for $24 \mathrm{~h}$. The bar graphs (a, $\mathbf{c}$, e) show the mean \pm s.d. $\left(n=3\right.$ ). The results are representative of three independent experiments. ${ }^{\star} P<0.05 ;{ }^{\star \star} P<0.001 ;{ }^{\star \star \star} P<0.0001$ (two-tailed unpaired Student's t-test) 
a
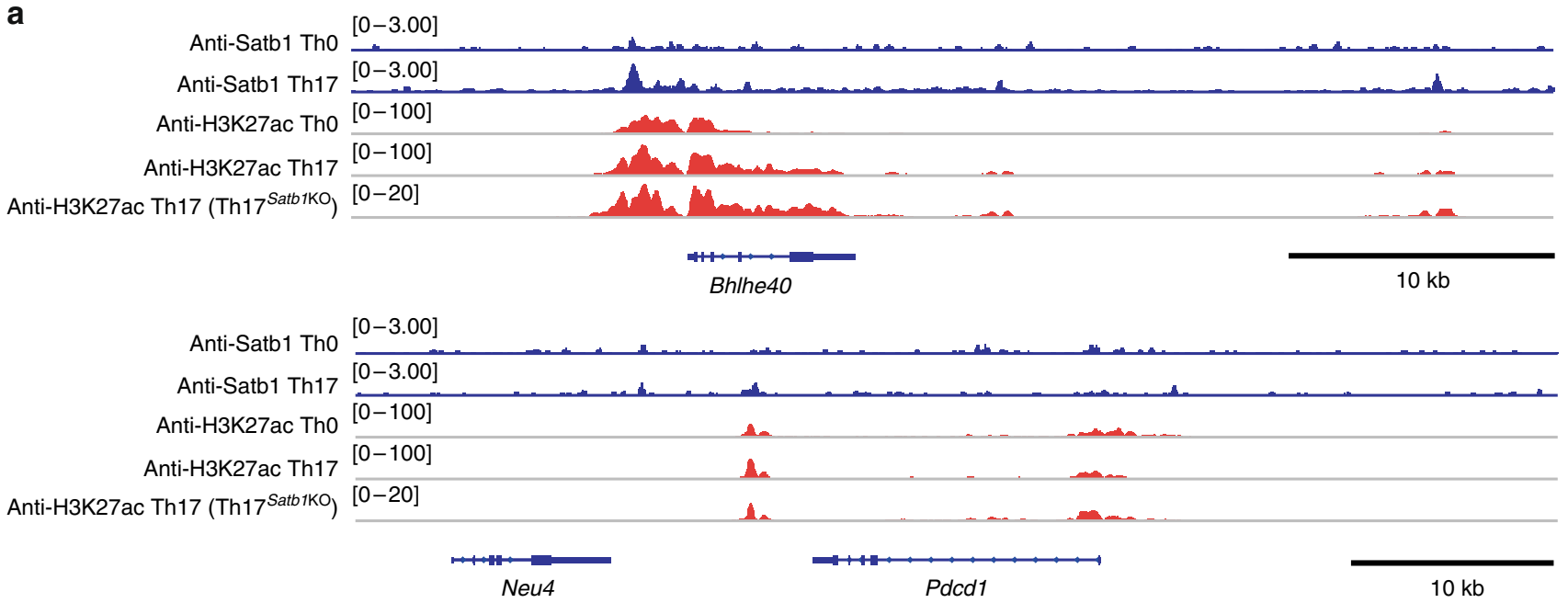

b

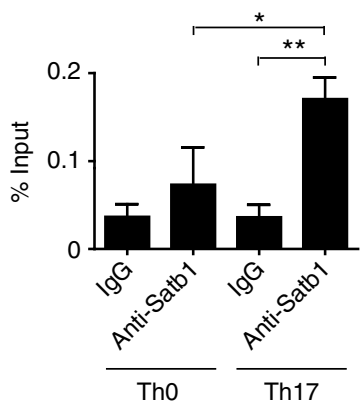

Fig. 7 Direct binding of Satb1 at the Bh/he40 active promoter region. a ChIP-seq analyses of Satb1 binding and H3K27ac modification at the Bhlhe40 and Pdcd1 loci in in vitro polarized Th0 or eYFP+ Th17 cells. b Quantitative ChIP-PCR analysis for Satb1 binding to the Bhlhe40 promoter region. Chromatin from in vitro polarized Th0 or eYFP+ Th17 cells was immune-precipitated with anti-Satb1 antibody or control lgG. Percent of input before IP (1\% gel input values) was quantified by real-time qPCR using primers specific for Bhlhe40 promoter region. The bar graph shows the mean \pm s.d. $(n=3)$. The results are representative of more than two independent experiments. ${ }^{\star} P<0.05$; ${ }^{\star \star} P<0.001$ (two-tailed unpaired Student's $t$-test)

Hence, in vivo phenotypes of Th17 cells, such as the activation status, migratory capacity, and maintenance of ROR $\gamma \mathrm{t}$ and IL-17 expression, were not significantly affected by Satb1 whereas among Bhlhe40, Blimp-1, GM-CSF, JunB, Gpr65, and Toso, as key pathogenic factors expressed by Th17 cells in EAE $^{18}, 19,27,44,45,54,55$, Satb1 specifically regulates GM-CSF in part via Bhlhe40 expression and down-regulates PD-1 expression for the acquisition of a pathogenic mode of Th17 cells.

The gene expression of Bhlhe 40 and PD-1 in effector T cells is controlled upon $\mathrm{T}$ cell activation and external environmental signals. CD28 stimulation is known to induce Bhlhe40 expression in $\mathrm{T}$ cells and IL-1R signaling further enhances it in Th17 cells $^{44,56}$. Given that Satb1-deficient Th17 cells express normal levels of IL-1R, reduced expression of Bhlhe 40 may be due to disruption of its transcriptional machinery mediated by a transcription factor complex with Satb1 downstream of IL-1R signaling pathway, resulting in impaired GM-CSF production by effector Th17 cells. Notably, the dysregulation of PD-1 by Satb1 was only observed in Th17 cells from the spinal cord in EAE mice, but not in those from the draining LNs and PPs. This Satb1-mediated regulation of PD-1 during inflammation is likely to be indirect since no direct binding of Satb1 to the Pdcd1 promoter region was detected. Inhibition of PD-1 occurs in CD8 $+\mathrm{T}$ cells through the recruitment of a nucleosome remodeling deacetylase repression complex by Satbl and is abrogated in tumor micro-environments ${ }^{42}$, suggesting that similar mechanisms may operate in Th17 cells in inflamed tissues of EAE. Because Satb1 alone is not sufficient to change the expression levels of PD-1, external environmental cues such as chronic IL-23 signaling in inflamed tissues may be necessary to not only upregulate the expression of Satb1, but also to modulate a mode of Satb1 function and dynamic chromatin architecture, shifting Th17 cells toward a pathogenic profile. On the other hand, in vitro treatment of TGF- $\beta$ increased Pdcd1 expression in Th17 cells, suggesting that TGF- $\beta$ enriched environment such as the intestine may maintain Satb1 expression low and in turn prevent the down-regulation of PD-1 in non-pathogenic Th17 cells (Supplementary Fig. 5). Further studies are necessary to investigate how particular environmental signals and specific co-factors dictate Satb1 function to regulate the effector profile in Th17 cells, and how Satb1-mediated chromatin loop organization occurs in gene loci related to Th17 cell pathogenicity.

Because Satb1 is a key regulator of Th17 pathogenicity and its GM-CSF production in autoimmune disease in mice, manipulating Satb1 gene expression or function may be a therapeutic target for various autoimmune diseases in light of accumulating evidence that GM-CSF-targeting treatments have been reported to be effective in clinical trials for patients with rheumatoid arthritis and multiple sclerosis ${ }^{57-61}$. Furthermore, a single nucleotide polymorphism (rs11719975) in a region near the human SATB1 gene has been recently associated with multiple sclerosis, suggesting an unappreciated link between SATB1 and the pathogenic function of effector $\mathrm{T}$ cells in the central nervous system of the patients ${ }^{62}$. However, the SATB1-mediated gene expression and effector program of human Th17 cells could differ in patients with different inflammatory diseases and at different 
clinical stages, and should carefully be assessed using clinical samples in the future study. Together, our findings, in addition to providing novel insights into the molecular mechanisms underlying the pathogenic program of tissue Th17 cells in mice, may help design novel immunotherapeutic approaches such as small molecule modifiers of Satb1 for the treatment of autoimmune diseases.

\section{Methods}

Mice. C57BL/6J mice were purchased from CLEA Japan. Rag2 ${ }^{-1-}$ mice have been previously described ${ }^{63}$. To generate Satb1 conditional knockout mice, we crossed Satb $1^{\mathrm{f} / \mathrm{fl}}$ mice with $I l 17 a^{\mathrm{Cre}} R 26 R^{\mathrm{eYFP}}$ or Thpok ${ }^{\mathrm{Cre}}$ mice, in which Satb1 is depleted in IL-17-producing $\mathrm{T}$ cells or peripheral $\mathrm{CD}^{+} \mathrm{T}$ cells, respectively $35,39,46,56$. All the mice used were on a C57BL/6 background and were maintained under SPF conditions in the animal facility at the Institute for Frontier Life and Medical Sciences, Kyoto University. Six to twelve-week-old mice were used for most of the experiments. Four-week-old mice were used for the analysis of thymocytes. All the experiments were approved by the animal ethical committee of the Institute for Frontier Life and Medical Sciences, Kyoto University and were performed in accordance with institutional guidelines.

Antibodies. The following antibodies were used for the flow cytometry analysis and cell sorting: CD4 (1:400, RM4-5, \#553051), CD8 (1:400, 53-6.7, \#553033), CD44 (1:400, IM7, \#553134), CD25 (1:200, PC61, \#562606), IL-2 (1:200, JES6-5H4, \#554428), IL-4 (1:200, 11B11, \#554435), IL-10 (1:200, JES5-16E3, \#554467), IL-17 (1:200, TC11-18H10, \#560184), GM-CSF (1:200, MP1-22E9, \#564747), PD-1 (1:200, J43, \#562584), CTLA-4 (1:200, UC10-4F10-11, \#553720), and GITR (1:200, DTA-1, \#558140) antibodies were purchased from BD Biosciences. Ki67 (1:100, anti-human, clone B56, \#556027), CD103 (1:100, M290, \#557495), and ICOS (1:200, 7E.17G9, \#552146) antibodies were purchased from BD Pharmingen. IFN- $\gamma$ (1:200, XMG1.2, \#25-7311-41), Foxp3 (1:200, FJK-16s, \#12-5773-82), LAG3 (1:200, C9B7W, \#17-2231-82), Tim3 (1:200, RMT3-23, \#12-5870-82), and KLRG1 (1:200, $2 \mathrm{~F} 1$, \#25-5893-82) antibodies were purchased from eBioscience. TIGIT (1:200, 1G9, \#142103) and Bcl2 (1:100, BCL/10C4, \#633503) antibodies were purchased from Biolegend. NGFR (1:800, NGFR5, \#MS-394-B1) and Live/Dead cell stain kit (\#L34955) were purchased from Thermo Fisher Scientific.

Cell preparation. For the preparation of double-positive (DP), $\mathrm{CD} 4^{+}$singlepositive (SP), and $\mathrm{CD} 8^{+} \mathrm{SP}$ thymocytes, $\mathrm{CD} 4^{+} \mathrm{CD} 8^{+}, \mathrm{CD} 4^{+} \mathrm{CD} 8^{-}$, and $\mathrm{CD} 4$ $\mathrm{CD}^{+}$thymocytes, respectively, were sorted using FACSAria (BD Bioscience). Peripheral naive $\left(\mathrm{CD} 44^{\text {low }} \mathrm{CD} 25^{-} \mathrm{CD} 4^{+}\right) \mathrm{T}$ cells, regulatory $\left(\mathrm{CD} 25^{\text {high }} \mathrm{CD} 4^{+}\right)$ T cells and effector (CD44high $\left.\mathrm{CD} 25^{-} \mathrm{CD} 4^{+}\right)$T cells were sorted from LNs and the spleen. $\mathrm{CD}^{+} \mathrm{eYFP}^{+} \mathrm{T}$ cells from the PPs of non-immunized mice or the spinal cord of EAE mice at the peak of the disease ( $14 \pm 3$ days after EAE induction) were sorted by FACSAria as non-pathogenic or pathogenic Th17 cells, respectively. CD4 $+\mathrm{eYFP}^{+} \mathrm{T}$ cells from draining LNs were sorted on day 7 after EAE induction. The pathogenic Th17 cells were prepared by mashing the spinal cord through a $70-\mu \mathrm{m}$ mesh filter, followed by $36.5 \%$ Percoll separation.

Cell culture. Purified $\mathrm{CD} 25^{-} \mathrm{CD} 44^{\text {low }} \mathrm{CD} 4^{+}$naive $\mathrm{T}$ cells were stimulated with plate-bound anti-CD3 $(1 \mu \mathrm{g} / \mathrm{ml} ; 2 \mathrm{C} 11$; BD Biosciences $)$ and anti-CD28 $(5 \mu \mathrm{g} / \mathrm{ml}$; 37.51; BD Biosciences) in IMDM supplemented with $10 \%$ FCS, $100 \mathrm{U} / \mathrm{ml}$ penicillin, $100 \mu \mathrm{g} / \mathrm{ml}$ streptomycin, $50 \mu \mathrm{M}$ 2-mercaptoethanol and $2 \mathrm{mM}$ L-glutamine in the presence of rmIL-12 (10 ng/ml, R\&D Systems) for Th1, rmIL-4 (10 ng/ml, R\&D Systems) and anti-IFN $\gamma(10 \mu \mathrm{g} / \mathrm{ml}$, Biolegend) for Th2, rhTGF- $\beta(10 \mathrm{ng} / \mathrm{ml}, \mathrm{R} \& D$ Systems) for iTregs, and rhTGF- $\beta(1 \mathrm{ng} / \mathrm{ml})$, rmIL-6 $(20 \mathrm{ng} / \mathrm{ml}$, R\&D Systems) and rmIL-1 $\beta$ ( $20 \mathrm{ng} / \mathrm{ml}$, R\&D Systems) for Th17 conditions and intracellular cytokine and Foxp3 staining was performed after $72-96 \mathrm{~h}$. In brief, for the cytokine staining, cells were restimulated for $2.5 \mathrm{~h}$ with PMA $(500 \mathrm{ng} / \mathrm{ml})$ and ionomycin $(500 \mathrm{ng} / \mathrm{ml})$ in the presence of brefeldin A $(1 \mu \mathrm{g} / \mathrm{ml})$. Fixation and permeabilization were followed by intracellular staining according to the manufacturer's instruction

(Thermo Fisher). Purified eYFP ${ }^{+}$Th17 cells $\left(1 \times 10^{6} / \mathrm{ml}\right)$ from the draining LNs of the EAE mice were stimulated with CD3/CD28 Dynabeads (Thermo Fisher) in the presence or absence of rmIL-1 $\beta(20 \mathrm{ng} / \mathrm{ml}, \mathrm{R} \& \mathrm{D}$ Systems), rmIL-6 $(20 \mathrm{ng} / \mathrm{ml}, \mathrm{R} \& \mathrm{D}$ Systems), rmIL-23 (100 ng/ml, R\&D Systems) or rhTGF- $\beta(10 \mathrm{ng} / \mathrm{ml})$ for $24 \mathrm{~h}$, and the cells were harvested for quantitative RT-PCR. Purified eYFP ${ }^{+}$Th17 cells $(5 \times$ $\left.10^{4} / \mathrm{ml}\right)$ from the spinal cord of EAE mice were stimulated with plate-bound antiCD3 $(1 \mu \mathrm{g} / \mathrm{ml})$ or BMDCs $\left(5 \times 10^{4} / \mathrm{ml}\right)$ in the presence of $\mathrm{MOG}_{35-55}$ peptide (50 $\mu \mathrm{g} / \mathrm{ml})$ and anti-PD-1 mAb $(20 \mu \mathrm{g} / \mathrm{ml} ; 29 \mathrm{~F} .1 \mathrm{~A} 12$ from Bio X cell) or an isotypematched control IgG2a (20 $\mu \mathrm{g} / \mathrm{ml}$; C1.18.4 from Bio X cell) for $24 \mathrm{~h}$ and cytokine concentrations in the supernatants were determined using a Cytometric Bead Array (BD Biosciences).

Generation of bone marrow-derived dendritic cells (BMDCs). Single cell suspensions of bone marrow cells from 4-8-week old C57BL/6J mice were prepared from the femur and tibia and subjected to red blood cell lysis with buffered ammonium chloride solution. Cells were then cultured at $1 \times 10^{6} / \mathrm{ml}$ in RPMI supplemented with $10 \%$ fetal calf serum, penicillin, streptomycin, and 2-ME in the presence of GM-CSF $(20 \mathrm{ng} / \mathrm{ml}$ ) (R\&D Systems). All media was removed and replaced with fresh media containing GM-CSF on day 3 and day 5 . By day 7, more than $80 \%$ of the resulting cells expressed CD11b and class II MHC and were used as antigen presenting cells.

EAE. In brief, mice were injected subcutaneously at two sites with an emulsion of $100 \mu \mathrm{l} \mathrm{CFA}$ and $250 \mu \mathrm{g}$ MOG peptide (amino acids 35-55). Mice received $200 \mathrm{ng}$ Bordetella pertussis (Calbiochem) intraperitoneally at day 0 and day 2 after EAE induction. An anti-PD-1 mAb (200 $\mu \mathrm{g} / \mathrm{mouse}$; 29F.1A12 from Bio X Cell) or a control IgG2a (200 $\mu$ g/mouse; C1.18.4 from Bio X Cell) antibody was intraperitoneally injected three times a week beginning at day 5 after EAE induction. The clinical scores were assessed daily as follows: 0 , unaffected; 1 , flaccid tail; 2 , impaired righting reflex and/or gait; 3 , partial hind limb paralysis; 4 , total hind limb paralysis; and 5, total hind limb paralysis with partial forelimb paralysis.

Quantitative RT-PCR. Total RNA was extracted and reverse-transcribed using TRIzol Reagent (Life Technologies) and SuperScript VILO (Invitrogen) according to the manufacturer's instruction. Quantitative RT-PCR was performed using TaqMan Gene Expression Assays (Thermo Fisher) and a Light cycler 480 (Roche) for the following genes: Bhlhe40 (Mm00478593_m1), Csf2 (Mm01290062_m1), Foxp3 (Mm00475162_m1), Hifla (Mm00468869_m1), Ikzf3 (Mm01306721_m1), Ifny (Mm01168134_m1), Il4 (Mm00445259_m1), Il17a (Mm00439618_m1), Il22 (Mm00444241_m1), Il23r (Mm00519943_m1), Nfkbiz (Mm00600522_m1), Pdcd1 (Mm01285676_m1), Prdm1 (Mm00476128_m1), Rorc (Mm01261022_m1), Satb1 (Mm01268937_m1), Tbx21 (Mm00450960_m1), and Hprt (Mm03024075_m1), as a housekeeping gene. The target gene expression was calculated by the comparative method for relative quantification after normalization to Hprt expression.

Cloning of Bhlhe40 and retroviral transduction. Murine Bhlhe 40 was amplified using $5^{\prime}$-TACGTAATGGAACGGATCCCCAGCGC-3' and 5'-GTCGACTTAGTCTTTGGTTTCTACGT-3' oligos and was cloned into the retroviral GCDN samI/N vector containing NGFR. The generation of retrovirus and the subsequent retroviral transduction were performed. In brief, retroviral plasmids were transfected into Plat-E cells using Fugene 6 (Promega) according to the manufacturer's instructions and retrovirus-containing supernatants were harvested $48 \mathrm{~h}$ after transfection. Magnetically sorted $\mathrm{CD} 4^{+} \mathrm{T}$ cells were activated with plate-coated anti-CD3/CD28 for day 3 and the cells were spin-infected with retroviral supernatants containing $2.5 \mu \mathrm{g} / \mathrm{ml}$ polybrene for $90 \mathrm{~min}$ at $32{ }^{\circ} \mathrm{C}$ in 24 -well plates at $1220 \mathrm{~g}$. The transduction efficiencies were assessed for NGFR expression, and the $\mathrm{NGFR}^{+} \mathrm{CD} 4^{+} \mathrm{T}$ cells were sorted on day 5 after transduction.

ChIP-sequencing. A total of $1-2.5 \times 10^{6}$ Th0 or eYFP + Th17 cells were induced in vitro under Th0 or Th17 culture conditions, and the cells were sorted for ChIPseq analysis ${ }^{34}$. In brief, sorted cells were cross-linked using $1 \%$ formaldehyde and lysed. Cross-linked DNA was fragmented by sonication and the lysate was incubated with anti-H3K27ac (GeneTex, GEX60815) or anti-Satb1 (Abcam, ab70004) antibodies (Thermo Fisher) captured by magnetic beads, followed by elution, reverse cross-link, and purification for ChIP-seq analysis according to the manufacturer's instructions. The ChIP-seq reads were mapped to the mouse genome $\mathrm{mm} 9$ Illumina iGenomes (http://support.illumina.com/sequencing/ sequencing_software/igenome.html) using Bowtie2 (version 2.2.1), and the ChIPseq peaks, normalized by total mapped read counts, were visualized in Integrative Genomics Viewer (Broad Institute).

Quantitative ChIP-PCR. A total of $1-2.5 \times 10^{6}$ Th0 or eYFP ${ }^{+}$Th17 cells were induced in vitro under Th0 or Th17 culture conditions, and the cells were sorted for ChIP-qPCR. ChIP-qPCR analysis was performed with anti-Satbl (Abcam, ab70004) antibody and control IgG (Abcam, ab171870) and the primers specific for the active promoter region of Bhlhe40 (5'-CAATGACGACTGACCCACCA-3' and $5^{\prime}$-CCCTGCAAGTTCGGAGAGTT- ${ }^{\prime}$ ).

RNA-sequencing. A total of $2 \times 10^{4} \mathrm{eYFP}^{+}$Th17 cells from the spinal cord of the control and Th17 5 atblKO EAE mice were sorted at the peak of the disease $(14 \pm$ 3 days after EAE induction) for RNA-seq analysis in duplicate. A total of $1 \times 10^{4}$ eYFP $^{+}$Th17 cells from the control and Th17 ${ }^{\text {SatblKO }}$ PPs of non-immunized mice were sorted for RNA-seq analysis in quadruplicate. In brief, total RNA was extracted and reverse-transcribed using RNeasy Micro Kit (Qiagen) and RNA-seq was performed using a SMART-seq v4 Ultra Low Input RNA Kit for Sequencing (Clonetech). The sequences were mapped to the mouse genome version $\mathrm{mm} 9$ using Hisat2. Differential gene expression analyses were performed using DESeq2 package in R (version 3.1.2) on tag counts obtained by HT-seq (version 0.6.1). The differentially expressed genes were defined with FDR less than 0.05 .

Statistical analysis. Two-tailed Student's $t$-test was used for most of the statistical analyses (GraphPad Prism), and a $P$ value of $<0.05$ was considered statistically significant. The clinical scores of EAE between each group were analyzed by twoway ANOVA with Bonferroni's post-test. 
Reporting summary. Further information on experimental design is available in the Nature Research Reporting Summary linked to this article.

\section{Data availability}

ChIP-seq and RNA-seq datasets are available under the accession numbers DRA006772 and DRA007314 in DNA Data Bank of Japan [http://ddbj.nig.ac.jp/ DRASearch/]. All relevant data are available upon reasonable request.

Received: 30 April 2018 Accepted: 7 January 2019

Published online: 01 February 2019

\section{References}

1. Stockinger, B. \& Omenetti, S. The dichotomous nature of T helper 17 cells. Nat. Rev. Immunol. 17, 535-544 (2017).

2. Gaffen, S. L., Jain, R., Garg, A. V. \& Cua, D. J. The IL-23-IL-17 immune axis: from mechanisms to therapeutic testing. Nat. Rev. Immunol. 14, 585-600 (2014).

3. Patel, D. D. \& Kuchroo, V. K. Th17 cell pathway in human immunity: lessons from genetics and therapeutic interventions. Immunity 43, 1040-1051 (2015).

4. Lai, Y. \& Dong, C. Therapeutic antibodies that target inflammatory cytokines in autoimmune diseases. Int. Immunol. 28, 181-188 (2016).

5. Atarashi, K. et al. ATP drives lamina propria $\mathrm{T}(\mathrm{H}) 17$ cell differentiation. Nature 455, 808-812 (2008).

6. Ivanov, I. I. et al. Induction of intestinal Th17 cells by segmented filamentous bacteria. Cell 139, 485-498 (2009).

7. Honda, K. \& Littman, D. R. The microbiota in adaptive immune homeostasis and disease. Nature 535, 75-84 (2016)

8. Bettelli, E. et al. Reciprocal developmental pathways for the generation of pathogenic effector TH17 and regulatory T cells. Nature 441, 235-238 (2006).

9. Mangan, P. R. et al. Transforming growth factor-beta induces development of the T(H)17 lineage. Nature 441, 231-234 (2006).

10. Veldhoen, M., Hocking, R. J., Atkins, C. J., Locksley, R. M. \& Stockinger, B. TGFbeta in the context of an inflammatory cytokine milieu supports de novo differentiation of IL-17-producing T cells. Immunity 24, 179-189 (2006).

11. Quintana, F. J. et al. Control of $\mathrm{T}(\mathrm{reg})$ and $\mathrm{T}(\mathrm{H}) 17$ cell differentiation by the aryl hydrocarbon receptor. Nature 453, 65-71 (2008).

12. Veldhoen, M. et al. The aryl hydrocarbon receptor links TH17-cell-mediated autoimmunity to environmental toxins. Nature 453, 106-109 (2008).

13. Dang, E. V. et al. Control of $\mathrm{T}(\mathrm{H}) 17 / \mathrm{T}(\mathrm{reg})$ balance by hypoxia-inducible factor 1. Cell 146, 772-784 (2011).

14. Shi, L. Z. et al. HIFlalpha-dependent glycolytic pathway orchestrates a metabolic checkpoint for the differentiation of TH17 and Treg cells. J. Exp. Med. 208, 1367-1376 (2011)

15. Kleinewietfeld, M. et al. Sodium chloride drives autoimmune disease by the induction of pathogenic TH17 cells. Nature 496, 518-522 (2013).

16. $\mathrm{Wu}, \mathrm{C}$. et al. Induction of pathogenic $\mathrm{TH} 17$ cells by inducible salt-sensing kinase SGK1. Nature 496, 513-517 (2013).

17. Ghoreschi, K. et al. Generation of pathogenic $\mathrm{T}(\mathrm{H}) 17$ cells in the absence of TGF-beta signalling. Nature 467, 967-971 (2010)

18. Codarri, L. et al. RORgammat drives production of the cytokine GM-CSF in helper $\mathrm{T}$ cells, which is essential for the effector phase of autoimmune neuroinflammation. Nat. Immunol. 12, 560-567 (2011).

19. El-Behi, M. et al. The encephalitogenicity of T(H)17 cells is dependent on IL1- and IL-23-induced production of the cytokine GM-CSF. Nat. Immunol. 12, 568-575 (2011).

20. Lee, Y. et al. Induction and molecular signature of pathogenic TH17 cells. Nat. Immunol. 13, 991-999 (2012).

21. Cua, D. J. et al. Interleukin-23 rather than interleukin-12 is the critical cytokine for autoimmune inflammation of the brain. Nature 421, 744-748 (2003).

22. Langrish, C. L. et al. IL-23 drives a pathogenic $\mathrm{T}$ cell population that induces autoimmune inflammation. J. Exp. Med. 201, 233-240 (2005).

23. McGeachy, M. J. et al. The interleukin 23 receptor is essential for the terminal differentiation of interleukin 17-producing effector T helper cells in vivo. Nat. Immunol. 10, 314-324 (2009).

24. Zheng, Y. et al. Interleukin-22, a T(H) 17 cytokine, mediates IL-23-induced dermal inflammation and acanthosis. Nature 445, 648-651 (2007).

25. Chung, Y. et al. Critical regulation of early Th17 cell differentiation by interleukin-1 signaling. Immunity 30, 576-587 (2009).

26. Sherlock, J. P. et al. IL-23 induces spondyloarthropathy by acting on ROR- $\gamma \mathrm{t}+$ CD3+CD4-CD8 - entheseal resident T cells. Nat. Med. 18, 1069-1076 (2012).

27. Gaublomme, J. T. et al. Single-cell genomics unveils critical regulators of Th17 cell pathogenicity. Cell 163, 1400-1412 (2015).
28. Wang, C. et al. CD5L/AIM regulates lipid biosynthesis and restrains Th17 cell pathogenicity. Cell 163, 1413-1427 (2015).

29. Alvarez, J. D. et al. The MAR-binding protein SATB1 orchestrates temporal and spatial expression of multiple genes during T-cell development. Genes Dev. 14, 521-535 (2000).

30. Mucida, D. et al. Transcriptional reprogramming of mature CD4(+) helper $\mathrm{T}$ cells generates distinct MHC class II-restricted cytotoxic T lymphocytes. Nat. Immunol. 14, 281-289 (2013).

31. Satoh, Y. et al. The Satb1 protein directs hematopoietic stem cell differentiation toward lymphoid lineages. Immunity 38, 1105-1115 (2013).

32. Kondo, M. et al. SATB1 plays a critical role in establishment of immune tolerance. I. Immunol. 196, 563-572 (2016).

33. Gottimukkala, K. P. et al. Regulation of SATB1 during thymocyte development by TCR signaling. Mol. Immunol. 77, 34-43 (2016).

34. Kitagawa, Y. et al. Guidance of regulatory $\mathrm{T}$ cell development by Satb1dependent super-enhancer establishment. Nat. Immunol. 18, 173-183 (2017).

35. Hirota, K. et al. Fate mapping of IL-17-producing T cells in inflammatory responses. Nat. Immunol. 12, 255-263 (2011).

36. Notani, D. et al. Global regulator SATB1 recruits beta-catenin and regulates $\mathrm{T}$ (H)2 differentiation in Wnt-dependent manner. PLoS Biol. 8, e1000296 (2010).

37. Park, $\mathrm{H}$. et al. A distinct lineage of $\mathrm{CD} 4 \mathrm{~T}$ cells regulates tissue inflammation by producing interleukin 17. Nat. Immunol. 6, 1133-1141 (2005).

38. Stromnes, I. M. \& Goverman, J. M. Active induction of experimental allergic encephalomyelitis. Nat. Protoc. 1, 1810-1819 (2006).

39. Hao, B. et al. An anti-silencer- and SATB1-dependent chromatin hub regulates Rag1 and Rag2 gene expression during thymocyte development. J. Exp. Med. 212, 809-824 (2015).

40. McGeachy, M. J. et al. TGF-beta and IL-6 drive the production of IL-17 and IL-10 by T cells and restrain T(H)-17 cell-mediated pathology. Nat. Immunol. 8, 1390-1397 (2007).

41. Lochner, M. et al. In vivo equilibrium of proinflammatory $\mathrm{IL}-17+$ and regulatory IL-10+ Foxp3+ ROR $\gamma \mathrm{t}+\mathrm{T}$ cells. J. Exp. Med. 205, 1381-1393 (2008).

42. Stephen, T. L. et al. SATB1 expression governs epigenetic repression of PD-1 in tumor-reactive T cells. Immunity 46, 51-64 (2017).

43. Kumar, P. P. et al. Functional interaction between PML and SATB1 regulates chromatin-loop architecture and transcription of the MHC class I locus. Nat. Cell Biol. 9, 45-56 (2007).

44. Martinez-Llordella, M. et al. CD28-inducible transcription factor DEC1 is required for efficient autoreactive $\mathrm{CD} 4+\mathrm{T}$ cell response. J. Exp. Med. 210 , 1603-1619 (2013).

45. Lin, C. C. et al. Bhlhe40 controls cytokine production by $\mathrm{T}$ cells and is essential for pathogenicity in autoimmune neuroinflammation. Nat. Commun. 5, 3551 (2014).

46. Okamoto, K. et al. IkappaBzeta regulates $\mathrm{T}(\mathrm{H}) 17$ development by cooperating with ROR nuclear receptors. Nature 464, 1381-1385 (2010).

47. Quintana, F. J. et al. Aiolos promotes TH17 differentiation by directly silencing Il2 expression. Nat. Immunol. 13, 770-777 (2012).

48. Schildberg, F. A., Klein, S. R., Freeman, G. J. \& Sharpe, A. H. Coinhibitory pathways in the B7-CD28 ligand-receptor family. Immunity 44, 955-972 (2016).

49. Yasui, D., Miyano, M., Cai, S., Varga-Weisz, P. \& Kohwi-Shigematsu, T. SATB1 targets chromatin remodellomg to regulate genes over long. Nature 419, 641-645 (2002).

50. Akiba, Y., Kuwabara, T., Mukozu, T., Mikami, T. \& Kondo, M. SATB1 is required for the development of experimental autoimmune encephalomyelitis to maintain $\mathrm{T}$ cell receptor responsiveness. Microbiol. Immunol. 62, 255-268 (2018).

51. Kakugawa, K. et al. Essential roles of SATB1 in specifying T lymphocyte subsets. Cell Rep. 19, 1176-1188 (2017).

52. Ciofani, M. et al. A validated regulatory network for Th17 cell specification. Cell 151, 289-303 (2012).

53. Sun, J. et al. SATB1 defines a subtype of cutaneous CD30(+) lymphoproliferative disorders associated with a T-helper 17 cytokine profile. $J$. Invest. Dermatol. 138, 1795-1804 (2018).

54. Jain, R. et al. Interleukin-23-induced transcription factor Blimp-1 promotes pathogenicity of T helper 17 cells. Immunity 44, 131-142 (2016).

55. Hasan, Z. et al. JunB is essential for IL-23-dependent pathogenicity of Th17 cells. Nat. Commun. 8, 15628 (2017).

56. Lin, C. C. et al. IL-1-induced Bhlhe40 identifies pathogenic $\mathrm{T}$ helper cells in a model of autoimmune neuroinflammation. J. Exp. Med. 213, 251-271 (2016)

57. Hartmann, F. J. et al. Multiple sclerosis-associated IL2RA polymorphism controls GM-CSF production in human TH cells. Nat. Commun. 5, 5056 (2014).

58. Constantinescu, C. S. et al. Randomized phase $1 \mathrm{~b}$ trial of MOR103, a human antibody to GM-CSF, in multiple sclerosis. Neurol. Neuroimmunol. Neuroinflamm. 2, e117 (2015). 
59. Behrens, F. et al. MOR103, a human monoclonal antibody to granulocytemacrophage colony-stimulating factor, in the treatment of patients with moderate rheumatoid arthritis: results of a phase Ib/IIa randomised, doubleblind, placebo-controlled, dose-escalation trial. Ann. Rheum. Dis. 74, 1058-1064 (2015).

60. Burmester, G. R. et al. A randomised phase IIb study of mavrilimumab, a novel GM-CSF receptor alpha monoclonal antibody, in the treatment of rheumatoid arthritis. Ann. Rheum. Dis. 76, 1020-1030 (2017).

61. Rasouli, J. et al. Expression of GM-CSF in T cells is increased in multiple sclerosis and suppressed by IFN-beta therapy. J. Immunol. 194, 5085-5093 (2015).

62. International Multiple Sclerosis Genetics Consortium. Analysis of immunerelated loci identifies 48 new susceptibility variants for multiple sclerosis. Nat. Genet. 45, 1353-1360 (2013).

63. Hori, S., Nomura, T. \& Sakaguchi, S. Control of regulatory T cell development by the transcription factor Foxp3. Science 299, 1057-1061 (2003)

\section{Acknowledgements}

The authors thank M. Matsuura and Y. Nakamura for technical assistance. The bioin formatics analyses were conducted using the facility at the Genome Information Research Center of the Research Institute for Microbial Diseases, Osaka University. This work was supported by JSPS Research Fellow (K.Y.), JSPS Grants-in-Aid for Scientific Research (S.S. and K.H.), and The Uehara Memorial Foundation (K.H.).

\section{Author contributions}

K.Y. designed, performed, and analyzed most of the experiments and wrote the manuscript. Y.K. performed the RNA-seq, ChIP-seq, and bioinformatical analyses and provided helpful suggestions. R.K. performed the RNA-seq, ChIP, ChIP-seq, and bioinformatical analyses. Y.I., H.W., G.K., and T.K.-S. provided intellectual input and animal resources. S.S. supervised the project. K.H. supervised the project, designed the experiments, and wrote the manuscript. All the authors reviewed the manuscript.

\section{Additional information}

Supplementary Information accompanies this paper at https://doi.org/10.1038/s41467019-08404-w.

Competing interests: The authors declare no competing interests.

Reprints and permission information is available online at http://npg.nature.com/ reprintsandpermissions/

Journal peer review information: Nature Communications thanks the anonymous reviewers for their contribution to the peer review of this work.

Publisher's note: Springer Nature remains neutral with regard to jurisdictional claims in published maps and institutional affiliations.

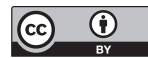

Open Access This article is licensed under a Creative Common Attribution 4.0 International License, which permits use, sharing, adaptation, distribution and reproduction in any medium or format, as long as you give appropriate credit to the original author(s) and the source, provide a link to the Creative Commons license, and indicate if changes were made. The images or other third party material in this article are included in the article's Creative Commons license, unless indicated otherwise in a credit line to the material. If material is not included in the article's Creative Commons license and your intended use is not permitted by statutory regulation or exceeds the permitted use, you will need to obtain permission directly from the copyright holder. To view a copy of this license, visit http://creativecommons.org/ licenses/by/4.0/.

(C) The Author(s) 2019 